\title{
ELECTRONIC AND GEOMETRIC STRUCTURE-FUNCTION CORRELATIONS OF THE COUPLED BINUCLEAR COPPER ACTIVE SITE
}

\author{
Edward I. Solomon \\ Department of Chemistry, Stanford University, Stanford, CA 94305 USA
}

\begin{abstract}
Chemical-spectroscopic studies of the coupled binuclear copper active site are presented which interpret the unique spectral features associated with oxyhemocyanin. These features are then used to generate a "spectroscopically effective" model for this active site. First the met apo [ $\mathrm{Cu}(\mathrm{II})-]$ and half met $[\mathrm{Cu}(\mathrm{II}) \mathrm{Cu}(\mathrm{I})]$ derivatives are spectroscopically compared; they demonstrate that exogenous ligands bridge the two coppers in the mixed valent form providing a pathway for electron delocalization. Detailed spectral studies are presented which probe the ground state wavefunction. Next, the dimer and met $[\mathrm{Cu}(\mathrm{II}) \mathrm{Cu}(\mathrm{II})]$ derivatives are compared to demonstrate that there is also an endogenous bridge between the two coppers. It provides a superexchange pathway for the antiferromagnetic coupling and is responsible for the EPR-nondetectable nature of the coupled binuclear cupric site. Finally, the unique optical features of oxyhemocyanin are interpreted as charge transfer transitions from a $\mu-1,2$ peroxide bridge.
\end{abstract}

These chemical-spectroscopic studies are then extended over the metalloproteins which contain a coupled binuclear copper active site and are involved in a variety of biological functions. Spectral studies of hemocyanin derivatives from the arthropod and mollusc phyla indicate that there is a structural distortion present at the arthropod site. This distortion interferes with exogenous ligand binding and correlates with the lack of catalase activity. A "spectral probe" derivative which contains a small fraction of EPR-detectable half met sites in the hemocyanin biopolymer is reported. This derivative is used to probe changes at the active site induced by shifts from relaxed to tensed protein quaternary structure. Parallel chemical-spectroscopic studies on tyrosinase are presented which indicate that its active site is extremely similar to that of the hemocyanins but highly accessible for coordination of organic substrates. An active site structural mechanism for the monooxygenation reaction is then proposed. Finally, these studies are extended to the coupled binuclear copper active site in the multicopper oxidase, laccase. Deoxy $[\mathrm{Cu}(\mathrm{I}) \mathrm{Cu}(\mathrm{I})]$, met $[\mathrm{Cu}(\mathrm{II}) \mathrm{Cu}(\mathrm{II})]$ and half met $[\mathrm{Cu}(\mathrm{II}) \mathrm{Cu}(\mathrm{I})]$ derivatives of the type-2-depleted enzyme form are studied; these allow correlation to the hemocyanins and tyrosinase. While the site is found to be similar with respect to the presence of an endogenous protein bridge and $\mathrm{N}$ and $\mathrm{O}$ ligation of the coppers, significant differences are observed which indicate that exogenous ligands do not bridge the two coppers. This appears to correlate to irreversible binding of the peroxide intermediate produced in the four-electron reduction of dioxygen to water.

\section{INTRODUCTION}

A coupled binuclear copper active site [1] exists in a variety of proteins and enzymes which perform different biological functions (Table 1). The hemocyanins reversibly bind dioxygen, exhibiting cooperative interactions between active sites in the protein biopolymer. The mollusc hemocyanins also exhibit catalase activity. Tyrosinase, in addition to reversibly binding dioxygen and dismutating peroxide, is also a monooxygenase capable of oxygenating a monophenol to an o-diphenol and further oxidizing this diphenol to the o-quinone. Finally, in the multicopper oxidases laccase, ceruloplasmin and ascorbic acid oxidase, there exists a coupled binuclear copper active site in addition to other types of copper centers. Together these sites couple four one-electron oxidations of substrate to the four-electron reduction of dioxygen to water.

The theme of this talk will be to first develop our chemical-spectroscopic approach [1,2,3] 
for one mollusc hemocyanin in order to elucidate the unique spectroscopic features associated with its coupled binuclear copper active site. These features will then be used to generate a "spectroscopically effective" picture [3] of this site. In the second half, this work will be extended over the proteins and enzymes contained in Table 1 in order to correlate changes in geometric and electronic structure with variation in active site function.

TABLE 1. Coupled binuclear copper containing proteins

\begin{tabular}{|c|c|c|}
\hline \multirow[t]{2}{*}{ Hemocyanin } & Arthropod & $\operatorname{deoxy}+\mathrm{O}_{2} \underset{\leftarrow}{ } \mathrm{oxy}$ \\
\hline & Mollusc & $\begin{array}{l}\text { deoxy }+\mathrm{O}_{2} \rightleftarrows \text { oxy } \\
2 \mathrm{H}_{2} \mathrm{O}_{2} \rightleftarrows \mathrm{O}_{2}+2 \mathrm{H}_{2} \mathrm{O}\end{array}$ \\
\hline Tyrosinase & & $\begin{array}{c}\text { deoxy }+\mathrm{O}_{2} \rightleftarrows \text { oxy } \\
2 \mathrm{H}_{2} \mathrm{O}_{2}+\mathrm{O}_{2}+2 \mathrm{H}_{2} \mathrm{O} \\
\text { phenol }+2 \mathrm{e}^{-}+\mathrm{O}_{2}+2 \mathrm{H}^{+} \underset{+}{+} \text {-diphenol }+\mathrm{H}_{2} \mathrm{O} \\
\text { 20-diphenol }+\mathrm{O}_{2} \rightleftarrows \text { 20-quinone }+2 \mathrm{H}_{2} \mathrm{O}\end{array}$ \\
\hline $\begin{array}{l}\text { Laccase } \\
\text { Cerulopla smir } \\
\text { Ascorbic Aci }\end{array}$ & & $4 \mathrm{AH}+\mathrm{O}_{2} \rightarrow 4 \mathrm{~A}+2 \mathrm{H}_{2} \mathrm{O}$ \\
\hline
\end{tabular}

The Resonance Raman spectrum of oxyhemocyanin [4] exhibits a peak at $744 \mathrm{~cm}^{-1}$ demonstrating that the dioxygen is bound as peroxide. Hence, the deoxy [ $\mathrm{Cu}(\mathrm{I}) \mathrm{Cu}(\mathrm{I})]$ site has been formally oxidized to two $\mathrm{Cu}(\mathrm{II})$ 's in oxy. One might then expect oxy to exhibit spectral features normally observed for copper (II) (Fig. 1).
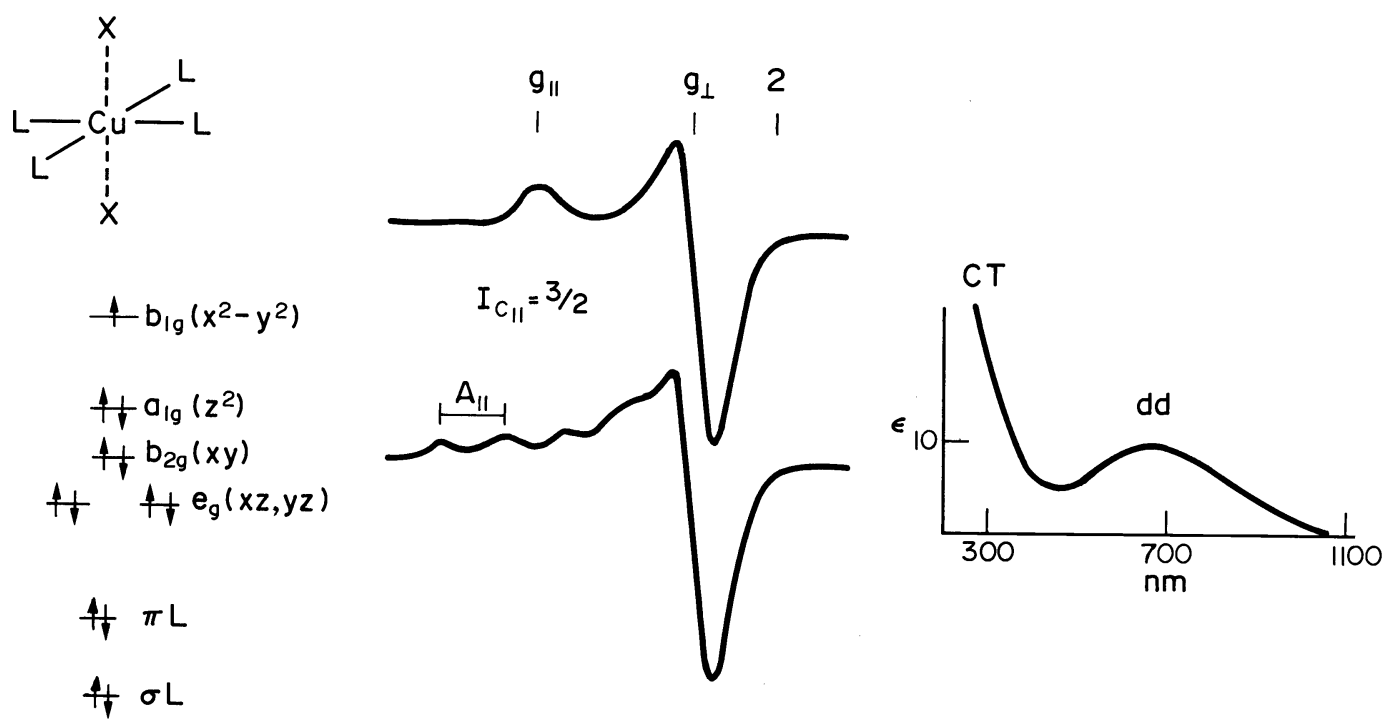

Fig. 1. Tetragonal cupric orbital energy level diagram (left), EPR spectra (middle), including hyperfine interaction (lower middle) and optical absorption spectrum (right).

Inorganic copper(II) complexes are usually found in a tetragonal geometry with four tightly bound equatorial ligands and weaker axial ligation. This crystal field produces the $d$

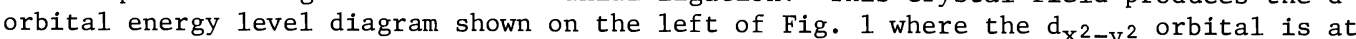
highest energy as it is oriented along the equatorial $\mathrm{Cu}-\mathrm{L}$ bonds. Addition of the nine $\mathrm{d}$

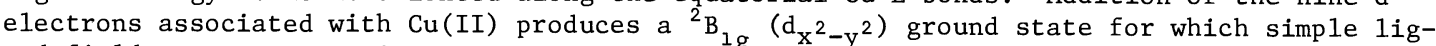
and field arguments require an EPR spectrum with $g_{\boldsymbol{\|}}>\mathrm{g}_{\boldsymbol{\Lambda}}>2$. Here $\mathrm{g}_{\boldsymbol{\mu}}$ relates to Zeeman 
splitting when the magnetic field is along the axial bonds and $g_{1}$ results from the magnetic field in the equatorial plane. As copper has a nuclear spin, $I_{N}=3 / 2$, which couples to the electron spin, each $g$ value is split into four hyperfine lines; this splitting (A) is often unresolved in the perpendicular region. The optical spectrum of tetragonal $\mathrm{Cu}$ (II) exhibits the four Laporte forbidden $d-d$ transitions as a composite broad weak band envelope centered at $\sim 700 \mathrm{~nm}\left(\varepsilon \cong 10 \mathrm{M}^{-1} \mathrm{~cm}^{-1}\right)$. To higher energy the absorption spectrum exhibits allowed, and therefore intense, charge transfer (CT) transitions which correspond to an electron being optically excited from filled ligand $\pi$ and $\sigma$ orbitals into the $d_{x^{2}-y^{2}}$ hole on the metal center.

From Fig. 2 it is clear that the spectral features of oxyhemocyanin are quite unique compared to normal inorganic copper(II) complexes. The binuclear copper site is EPR-nondetectable and diamagnetic to the most sensitive SQUID magnetometers [5]. Further, in the optical spectrum, in contrast to the broad weak absorption at $\sim 700 \mathrm{~nm}$, oxyhemocyanin exhibits an intense transition $\left(\varepsilon \cong 1000 \mathrm{M}^{-1} \mathrm{~cm}^{-1}\right.$ ) at $\sim 600 \mathrm{~nm}$ and an extremely intense $(\varepsilon \cong 20,000$ $\mathrm{M}^{-1} \mathrm{~cm}^{-1}$ ) band at $350 \mathrm{~nm}$. Clearly one has an interesting spectroscopic problem further complicated by the binuclear nature of the active site.

Our approach [1] to this problem has been to generate a series of active site derivatives (Fig. 3) which allows us to systematically vary this site. We then use these derivatives as perturbations for a variety of spectroscopic studies. The simplest derivative is met apo $[6,7]$ where one copper is removed and the remaining one is oxidized and exhibiting all the usual spectral features associated with tetragonal $\mathrm{Cu}$ (II). Next in complexity is the mixed valent half met [7,8] form where the copper(II) can be studied directly, as described above. The copper(I), while $\mathrm{d}^{10}$ and thus spectroscopically inaccessible by EPR and optical methods, can still be investigated by comparison to the met apo derivative. Finally, two derivatives contain binuclear cupric sites. Dimer $[9,11]$ has a large EPR signal associated with two weakly (dipolar) interacting tetragonal $\mathrm{Cu}(\mathrm{II})$ 's while the met derivative $[10,11]$, 1ike oxyhemocyanin, is EPR-nondetectable.

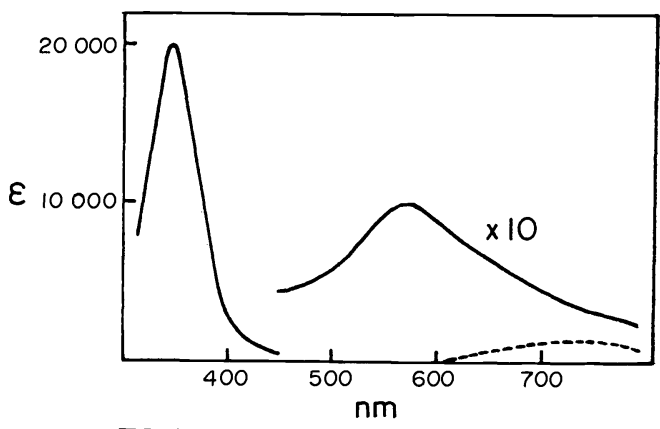

\section{DEOXY}

\section{$\mathrm{Cu}^{+1} \mathrm{Cu}+1$}

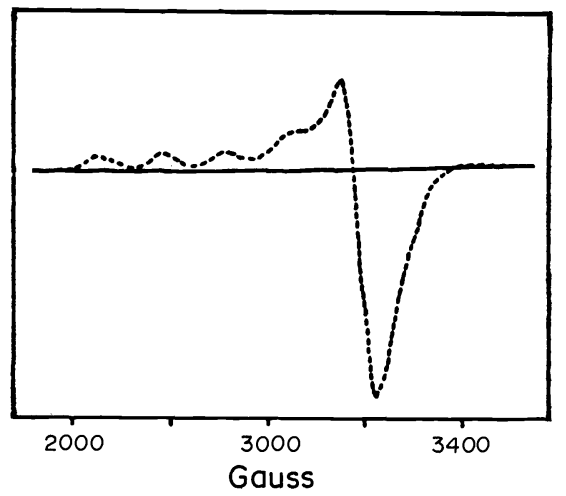

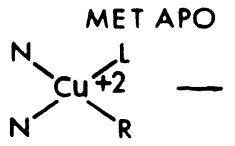

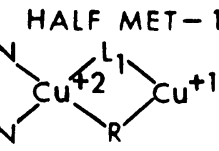

HALF APO

$$
\mathrm{Cu}+1
$$

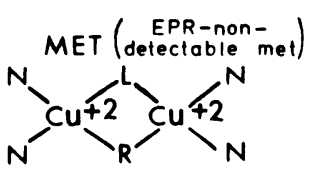

HALF MET - 2<smiles>[R][C-]([Te])[Z17]([Z6])(N)N</smiles>

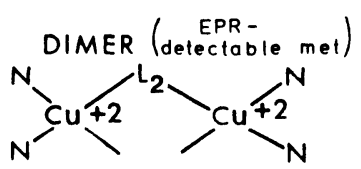

Fig. 2

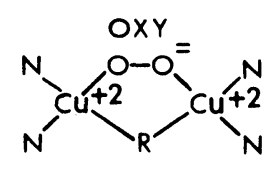

Fig. 3

Fig. 2. Oxyhemocyanin $(-)$ and normal tetragonal cupric (- - -) optical absorption (upper) and EPR (lower) spectra.

Fig. 3. Site derivatives of the coupled binuclear copper active site ( $\mathrm{L}$ = exogenous ligand, $\mathrm{R}$ = endogenous bridge). 
The chemical-spectroscopic studies which have allowed us to generate the "spectroscopically effective" model of the oxyhemocyanin active site shown at the bottom of Fig. 3 will now be summarized. First, a comparison of the met apo and half met derivatives will be used to demonstrate that exogenous ligands bridge the two copper centers. Next, a comparison of the dimer and met forms will demonstrate that there is also an endogenous protein bridge responsible for the lack of an EPR signal. Finally, the unique optical spectrum of oxy will be assigned and used to strongly support a $\mu-1,2$ peroxide bridging mode for oxyhemocyanin.

\section{CHEMICAL-SPECTROSCOPIC STUDIES}

Met apo - half met: the exogenous bridge

Figure 4 presents the chemical evidence $[6,7,8]$ which first indicated that exogenous ligands

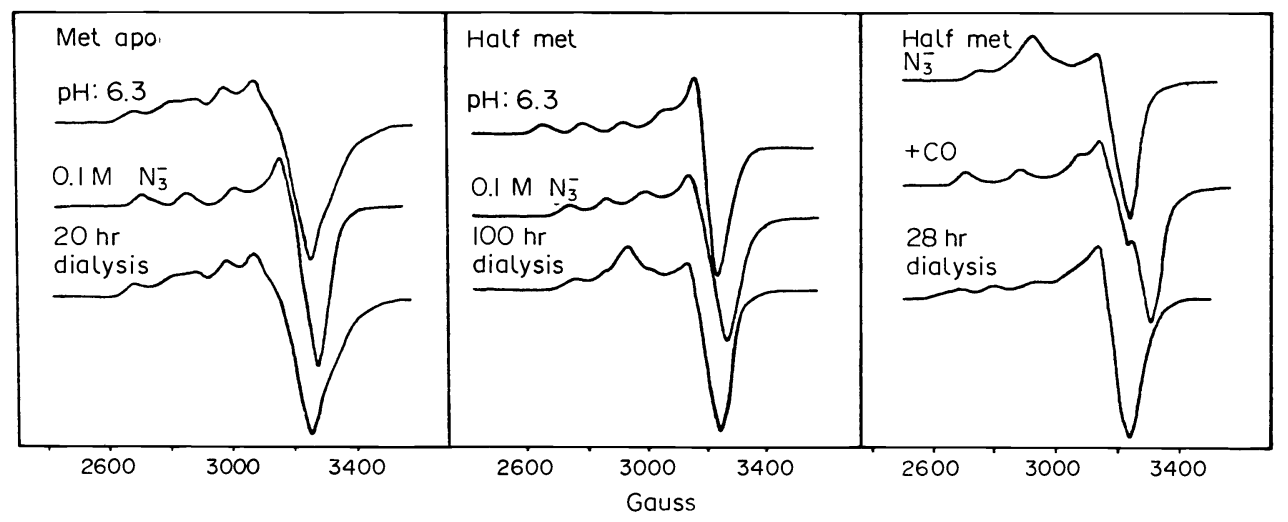

Fig. 4. EPR spectra (77K) of met apo (left) and half met (middle and right) hemocyanin derivatives under the conditions indicated.

bind to both copper ions. Here, EPR signals are being used analytically to detect ligand binding at the active site. In the case of met apo (Fig. 4, left), addition of the exogenous ligand azide causes the EPR signal to change, indicating that $\mathrm{N}_{3}{ }^{-}$is bound to the $\mathrm{Cu}$ (II). Dialysis readily removes the $\mathrm{N}_{3}{ }^{-}$and restores the original EPR signal. Hence, met apo exhibits labile ligand substitution chemistry normally found for equatorial binding to tetragonal $\mathrm{Cu}(\mathrm{II})$. This is in strong contrast to the behavior observed for the half met derivative (Fig. 4, middle). Addition of excess $\mathrm{N}_{3}^{-}$again produces a large EPR change, but now extensive dialysis produces a signal different from the original and indicative of one azide remaining tightly bound to the active site. Thus, the presence of the $\mathrm{Cu}(\mathrm{I})$ greatly increases the affinity for the exogenous ligand at the site. Further, reversible coordination of $\mathrm{CO}$ to the copper(I) in half met- $\mathrm{N}_{3}-$ (Fig. 4, right) produces a large change in the $\mathrm{Cu}$ (II) EPR signal. Short-term dialysis under CO pressure results in a further change of this signal which indicates that the azide has now been labilized. Thus, in half met the exogenous ligand clearly binds to the $\mathrm{Cu}(\mathrm{II})$ based on a variety of spectral features (e.g., $\mathrm{N}_{3}{ }^{-} \rightarrow$ $\mathrm{Cu}(\mathrm{II}) \mathrm{CT}$ at $\sim 500 \mathrm{~nm}$ ) while the $\mathrm{Cu}(\mathrm{I})$ is also implicated in bonding based on its stabilization, relative to met apo, of $\mathrm{N}_{3}^{-}$at the active site and ligand labilization upon $\mathrm{CO}$ coordination to the $\mathrm{Cu}(\mathrm{I})$.

Figure 5 presents the spectroscopic evidence [7] for the half met derivative which clearly demonstrates that exogenous ligands bridge the two coppers. First, as one proceeds down this half met series, the EPR signals progressively deviate from that of normal $\mathrm{Cu}$ (II), as revealed by more than four parallel hyperfine features and, in the case of $\mathrm{N}_{3}{ }^{-}$, an approximately isotropic signal. This indicates significant electron delocalization onto the second copper. Optically, in addition to $d-d$ and CT transitions of normal copper(II), a new low energy feature appears which gains in intensity down the series in Fig. 5. This is an intervalence transfer (IT) transition where one electron is optically excited from the $\mathrm{Cu}(\mathrm{I})$ to the $\mathrm{Cu}(\mathrm{II})$ in a class II mixed valence complex. The intensity of this IT transition and EPR hyperfine coupling to the second copper both correlate with the covalent character of the tightly bound exogenous ligand $\left(\mathrm{F}^{-}<\mathrm{Cl}^{-}<\mathrm{Br}^{-}<\mathrm{I}^{-}<\mathrm{N}_{3}^{-}\right)$. This requires that it provide the pathway for electron delocalization and hence bridge the two coppers. 

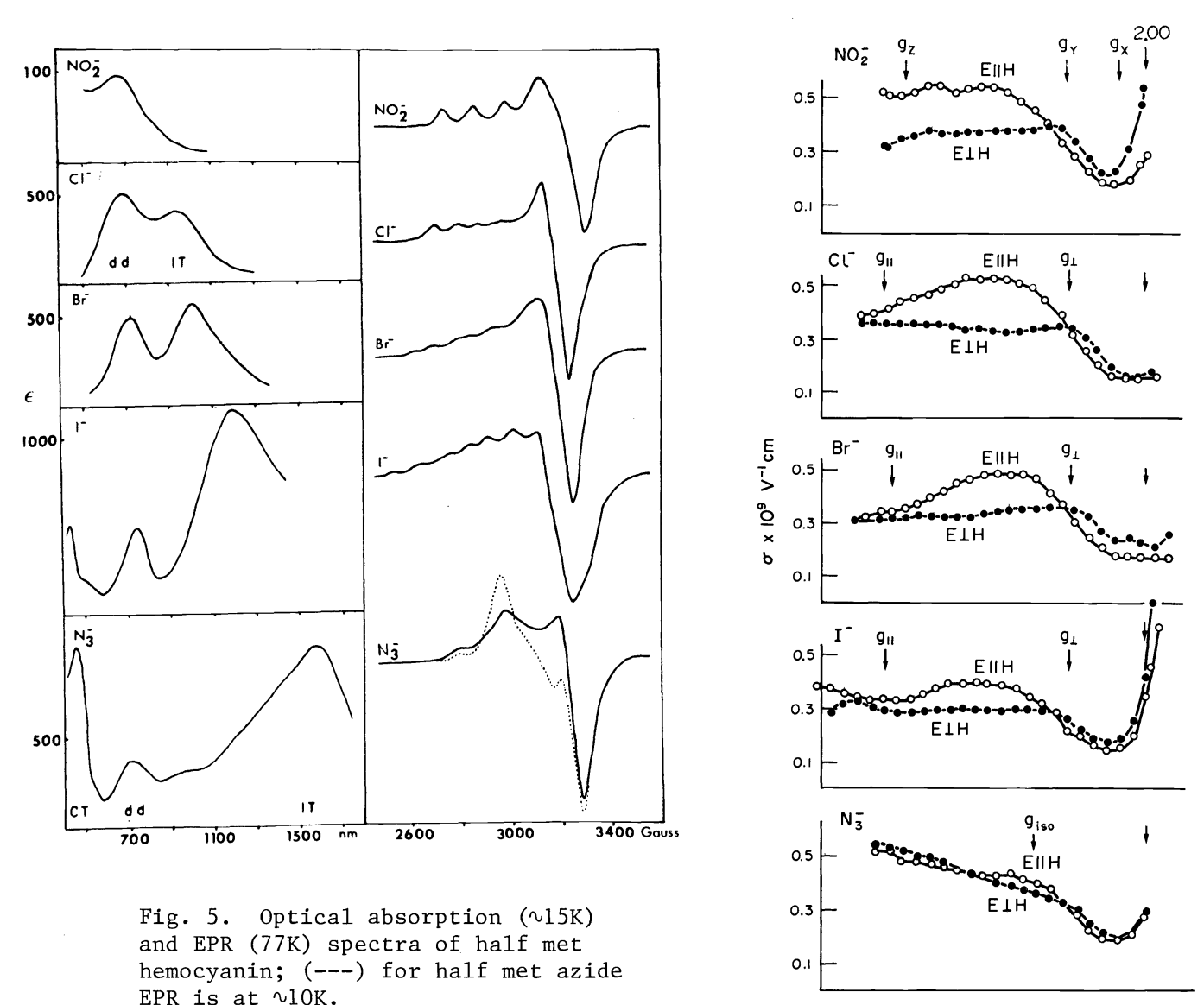

Fig. 5. Optical absorption ( $15 \mathrm{~K})$ and EPR (77K) spectra of half met hemocyanin; (---) for half met azide EPR is at $\sim 10 \mathrm{~K}$.

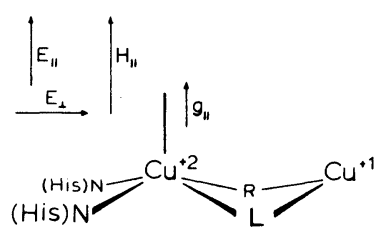

Fig. 6

Fig. 6. Linear Electric Field Effect on half met hemocyanin showing the relative "shift" $(\sigma)$ in $g$ value for $\mathrm{E} \| \mathrm{H}(\mathrm{O}-\mathrm{O}-\mathrm{O})$ and $\mathrm{E} \perp \mathrm{H}(\cdot-\cdot-\cdot)$. Spectra are correlated at $g=2.00$, and $g$ values of the associated EPR spectra are indicated. Active site structural symmetry is indicated at bottom.

We have recently been involved [12] in further probing the nature of the ground state wavefunction in this mixed valent system. In collaboration with Dr. William Mims, Bell Labs, we have studied the Linear Electric Field Effect (LEFE) [13] on the g values using spin echo techniques. Here we are probing the odd parity components mixed into the ground state. In the case of the localized half met- $\mathrm{NO}_{2}^{-}$(Fig. 6, top), one observes the largest shift ( $\sigma$ ) in $\mathrm{g}$ value when the $\mathrm{E}$ field is parallel to $\mathrm{H}$ at $\mathrm{g}_{\boldsymbol{\mu}}$. This indicates that the Cu(II) site is of

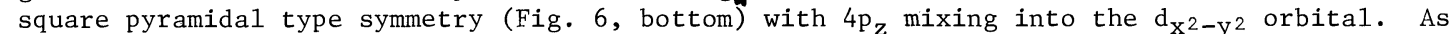
one proceeds down the half met series (Fig. 6), varying the extent of electron delocalization, the maximum LEFE is found to move toward $g_{l}$. Thus, the exogenous bridge mixes odd parity character into the ground state. Comparative analysis of optical features indicates that it is the $\mathrm{I}^{-} \rightarrow \mathrm{Cu}$ (II) CT rather than the IT transition which is directly correlating with this shift. This is consistent with a superexchange description for electron delocalization between the two coppers. 
Dimer-met: the endogenous bridge

Before proceeding to use the formally binuclear cupric met and dimer derivatives to demonstrate that an endogenous protein bridge is also present at the coupled binuclear copper active site, we begin by reviewing the spectral effects of binuclear cupric interactions. In the limit of two very close copper(II)'s (Fig. 7, left) one would expect direct overlap between d orbitals on the two metal ions. New molecular orbitals of binuclear complex would be formed where the interaction energy would be on the order of $10,000 \mathrm{~cm}^{-1}$. This would produce a completely diamagnetic ground state and dramatically change the optical spectrum.
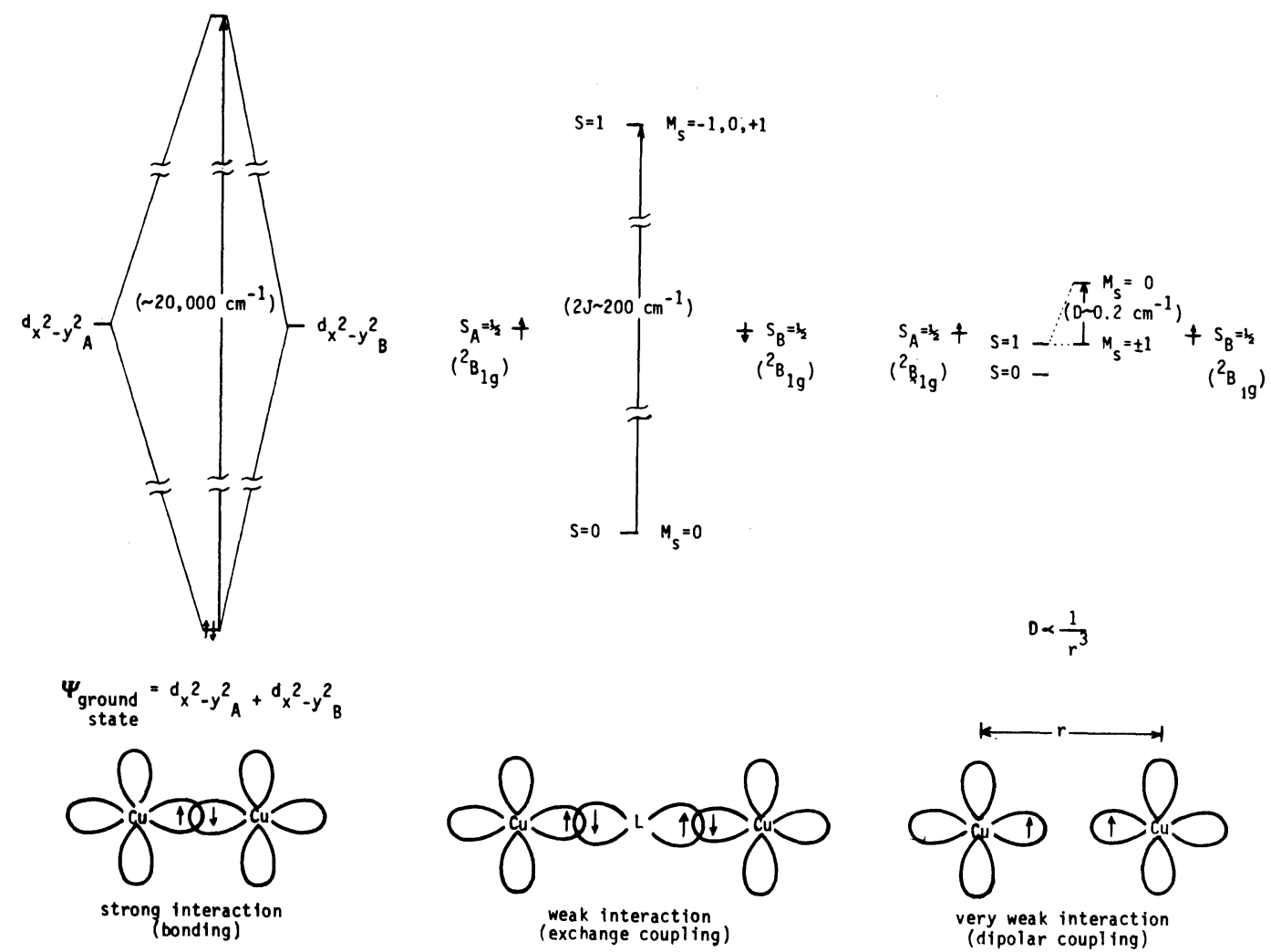

Fig. 7. Three limits of $\mathrm{Cu}(\mathrm{II})-\mathrm{Cu}(\mathrm{II})$ interaction with associated electronic energy levels.

In the middle of Fig. 7, we consider the two coppers far enough apart so that there is no direct overlap but now include a bridging ligand. This bridge provides a superexchange pathway between the two $\mathrm{d}^{9}$ ions and allows antiferromagnetic coupling. Exchange coupling interaction is more clearly viewed in the valence bond description where there is little effect on the d orbitals of each copper(II), but the two unpaired spins (one on each ion) couple to produce a singlet and a triplet state. Antiferromagnetic interaction can cause the triplet to be hundreds of wavenumbers above the singlet leading to a diamagnetic ground state at room temperature with little effect on the molecular orbital diagram, and hence, the optical spectrum.

If the coppers are far enough apart to eliminate direct overlap and a bridging ligand is not present (Fig. 7, right), the copper ions can only interact through dipolar coupling. This interaction is only on the order of $0.1 \mathrm{~cm}^{-1}$, and thus produces a paramagnetic ground state but can dramatically affect the EPR signal (Fig. 8). This dipolar coupling produces a zero field splitting of the spin triplet which depends on $1 / \mathrm{r}^{3}$. When the coppers are $>7 \AA$ apart, this interaction is minimal, and only a normal $\mathrm{AM}_{\mathrm{s}}^{\mathrm{s}}= \pm 1$ tetragonal $\mathrm{Cu}(\mathrm{II})$ EPR spectrum is observed. As the two coppers move closer together this $\Delta \mathrm{M}_{\mathrm{S}}= \pm 1$ transition broadens and eventually splits, and a forbidden $\Delta \mathrm{M}_{\mathrm{S}}= \pm 2$ transition becomes weakly allowed. When the coppers are quite close together, the zero field splitting can dominate, producing a broad EPR signal extending over a large magnetic field region. 


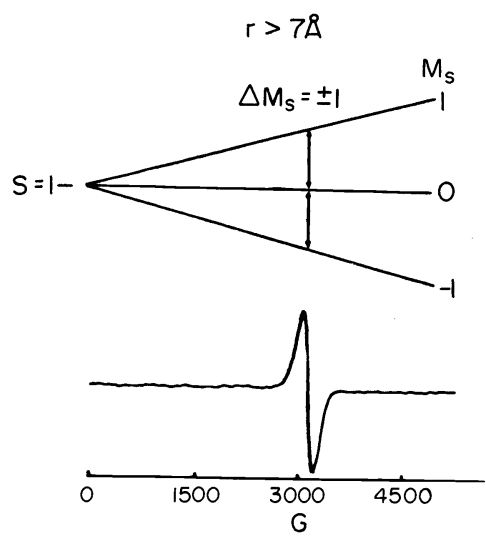

$r=4 \AA$

$\Delta M_{S}= \pm 1$
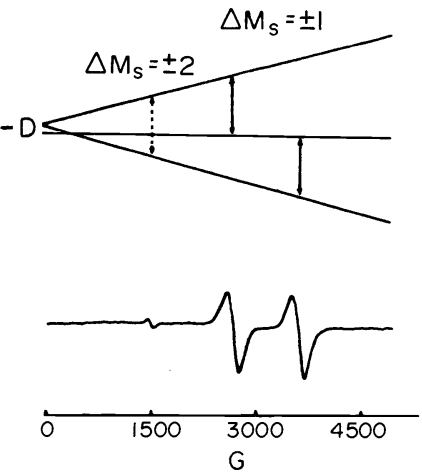

$r=3 \AA$
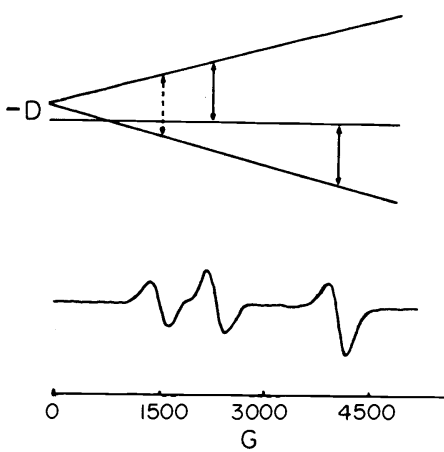

Fig. 8. Zero field splitting (D) of the triplet EPR signals of a dipolar-coupled binuclear cupric site at three metal-metal separations; allowed $\Delta M_{S}= \pm 1$ (solid lines) and forbidden $\Delta \mathrm{M}_{\mathrm{S}}= \pm 2$ (broken lines) transitions are indicated; anisotropy and hyperfine contributions are neglected.

Keeping this overview of binuclear copper interactions in mind, we now proceed with spectral studies on the dimer and met derivatives. Dimer [1,9] is obtained from the reaction of deoxy with $\mathrm{NO}$ and $\mathrm{O}_{2}$ and is characterized by the EPR signal shown in Fig. 9A: a broad $\Delta \mathrm{M}_{\mathrm{S}}=$ \pm 1 transition and the appearance of a weak $\Delta \mathrm{M}_{\mathrm{s}}= \pm 2$ transition at half field. As the temperature dependence of this signal [14] indicates there is negligible exchange coupling $\left(|2 \mathrm{~J}|<5 \mathrm{~cm}^{-1}\right)$, the dimer active site contains two dipolar interacting cupric ions. Simulation of this EPR spectrum [14] indicates the coppers are separated by $\sim 6 \AA$. Substitution of the dimer exogenous ligand with other ligands [11] which sustain a $\mathrm{Cu}-\mathrm{Cu}$ separation of $>5 \AA$ (e.g., $\mathrm{N}_{3}{ }^{-}$; Fig. 9B) also produces characteristic dipolar-coupled cupric EPR signals. Removal of these "group 2" ligands [11] by dialysis results in the weak EPR signal (Fig. 9C) associated with the met derivative (vide infra).

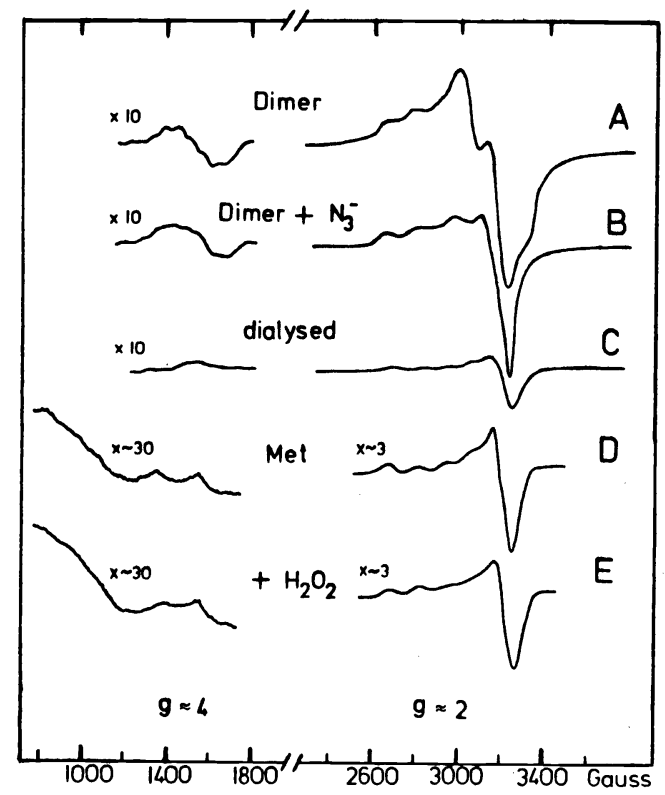

Fig. 9. EPR spectra (77K) of A. dimer, B. dimer $+\mathrm{N}_{3}^{-}$, C. dialysed dimer, D. met, E. met $+\mathrm{H}_{2} \mathrm{O}_{2}$ hemocyanin in the $\mathrm{g} \cong 2$ and $\mathrm{g} \cong 4$ regions. 
The met form of hemocyanin is normally prepared [1,10] by associative ligand displacement of peroxide from the oxy site, and hence formally contains two $\mathrm{Cu}(\mathrm{II})$ 's. This derivative exhibits the weak EPR signal shown at higher sensitivity in Fig. 9D. While it is not possible to spectroscopically quantify the features in the $\mathrm{g} \cong 4$ region, met can be titrated back to $290 \%$ EPR-nondetectable oxy sites with no change in the EPR spectrum (Fig. 9E) [11]. Therefore met, like oxy, is EPR-nondetectable; the weak signals of Fig. 9D are associated with $\leqslant 10 \%$ of the met sites and will be addressed later. Thus, we have two formally binuclear cupric derivatives of the hemocyanin active site: dimer which exhibits a large dipolarcoupled EPR signal and met which is EPR-nondetectable.

The binuclear cupric interaction in met can be determined through the optical spectral comparison shown in Fig. 10. The ligand field region of dimer is simply that of two tetragonal copper(II)'s. Comparison to met indicates there is no change in energy of these d-d transitions. Thus, the interaction in the met derivative responsible for the lack of an EPR signal must only weakly perturb the d orbitals. This requires antiferromagnetic coupling (Fig. 7, middle) and therefore an endogenous protein bridge. Active site representations are shown in Fig. 11. In dimer, group 2 ligands [1,7] keep the coppers $\gtrsim 5 \AA$ apart, breaking the endogenous bridge and leading to EPR signals of a dipolar-coupled binuclear cupric site. Removal of these group 2 ligands results in a Cu-Cu distance of $\leqslant 4 \AA$, and allows the endogenous bridge to reform, thus providing a superexchange pathway for antiferromagnetic coupling and elimination of the EPR signals.

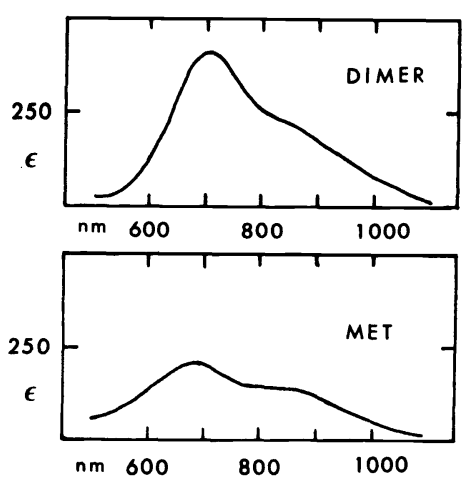

Fig. 10. Ligand field optical absorption ( $15 \mathrm{~K}$ ) spectra of dimer and met hemocyanin.

Met<smiles></smiles>

$\mid r-4 \AA \rightarrow$
Dimer<smiles>C[Ge](C)(N)[Te]C(N)(N)N</smiles><smiles>C[Te][As]=[Te]C</smiles>

Fig. 11. Active site representations for the met and dimer derivatives.

We now return to the weak EPR signals associated with the met derivative [15] in order to further probe the endogenous bridge. The $\mathrm{g} \cong 2$ feature is due to a small number (usually $<3 \%$ ) of irreversibly damaged sites, and is not considered further. The signals seen at $g \cong 4$ however, are associated with a heterogenous fraction $(\$ 10 \%)$ of the active sites wherein the endogenous bridge is strained, lowering its stability constant. At low pH, azide and acetate compete with and displace the endogenous protein bridge in these sites (Fig. 12, 
left). This protonation and displacement results in broad EPR signals (Fig. 12, right) whose temperature dependence indicates no exchange coupling. The distance between the dipolar interacting cupric ions in these unique sites is modified by the exogenous ligand;
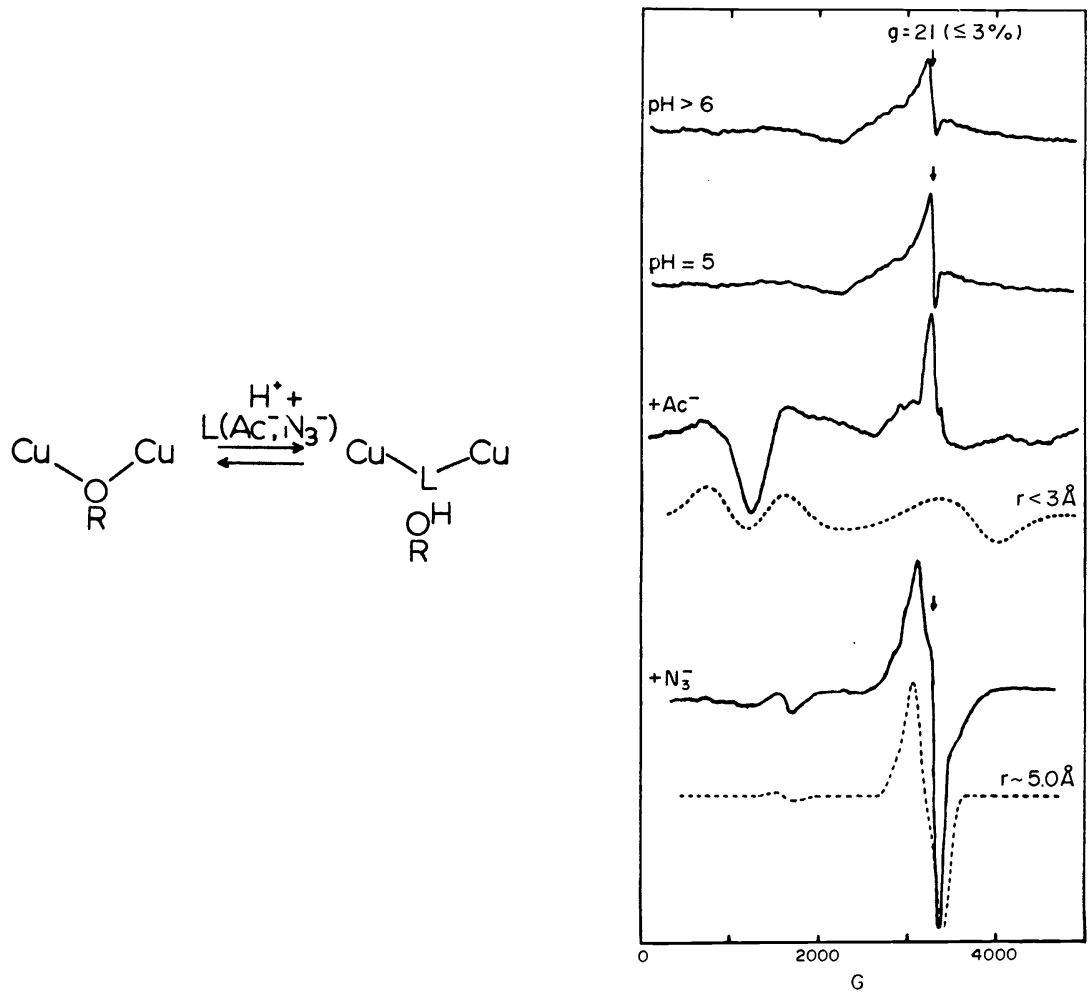

Fig. 12. EPR spectra ( $10 \mathrm{~K})$ of met hemocyanin at (top to bottom) $\mathrm{pH}>6.0, \mathrm{pH}=5.0$ + acetate and $\mathrm{pH}=5.0+$ azide. The weak signal at $\mathrm{g} \cong 2.1$ corresponds to $<3 \%$ irreversibly damaged sites. (--) are dipolar-coupled binuclear copper(II) simulations with $r<3 \AA$ (acetate) and $r \cong 5 \AA$ (azide).

with acetate the coppers are quite close and the associated large zero field splitting spreads the EPR absorption over $\sim 5000$ Gauss while the group 2 ligand azide shows signals indicative of $\sim 5 \AA$ separation. From a pH dependent competitive displacement study of the apparent stability constant of the endogenous bridge, we estimate its intrinsic $\mathrm{pK}_{\mathrm{a}}$ to be $>7$. This eliminates carboxylate, and together with EXAFS data [16] which excludes first shell sulfur coordination, suggests that the likely candidates for $\mathrm{RO}^{-}$are phenolate, hydroxide or perhaps alkoxide.

Oxyhemocyanin

With a reasonable interpretation of the unique ground state magnetic properties of oxyhemocyanin, we now consider its unique optical spectrum. The appropriate spectral comparison is to the met derivative shown in Fig. 13. Removal of peroxide eliminates the two dominant spectral features at $\sim 600$ and $\sim 350 \mathrm{~nm}$, and therefore they can be clearly assigned as $\mathrm{O}_{2}=\rightarrow \mathrm{Cu}(\mathrm{II})$ CT transitions. Ligand field transitions of tetragonal $\mathrm{Cu}(\mathrm{II})$ remain at

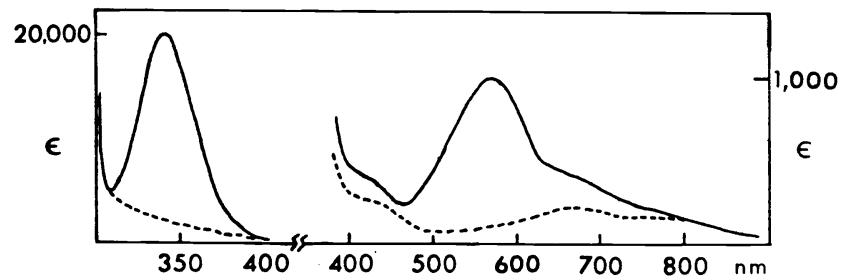

Fig. 13. Optical absorption $(\sim 15 \mathrm{~K})$ of oxy $(-)$ and met (--) hemocyanin. 
$\sim 700 \mathrm{~nm}$, as does a band at $420 \mathrm{~nm}$. From model studies (see Ref. 2), this is likely a phenolate $\rightarrow \mathrm{Cu}$ (II) CT transition and may be due to the endogenous protein bridge. We now have the interesting spectroscopic problem of predicting the charge transfer spectrum of peroxide bridging two $\mathrm{Cu}(\mathrm{II})$ 's and then using this spectrum to distinguish between the two possible bridging geometries shown at the top of Fig. 14.

\section{DIMER}
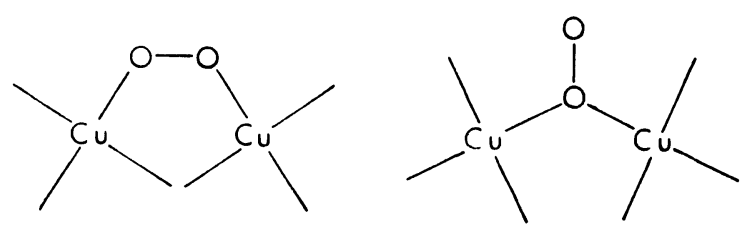

\section{MONOMER}
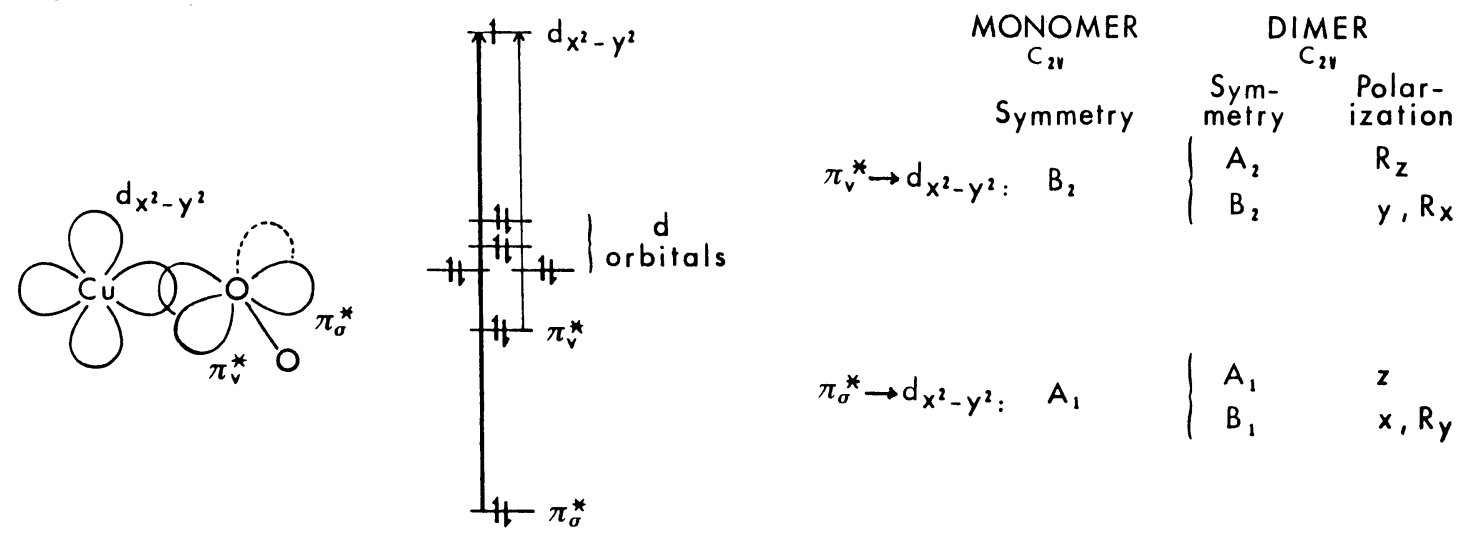

Fig. 14. (Upper) Two possible peroxide bridging geometries; (lower left) energy levels and $\mathrm{O}_{2}=\rightarrow \mathrm{Cu}(\mathrm{II})$ CT transitions for a copper(II)-peroxide monomer; (lower right) correlation from the monomer to a dimer indicating symmetries and polarizations of the dimer $\mathrm{O}_{2}=\mathrm{Cu}(\mathrm{II})$ CT transitions.

We approach this problem by first considering the CT spectrum of a peroxide bound to a single Cu(II) (Fig. 14, left). Here, the highest energy occupied orbital on the peroxide ( $\left.\pi^{*}\right)$ splits into two levels upon coordination; the $\pi *_{\sigma}$ is involved in $\sigma$ bonding to the $d_{x^{2}}-y^{2}$ orbital and found to deeper binding energy relative to the $\pi *_{\mathrm{v}}$ which is only involved in $\pi$

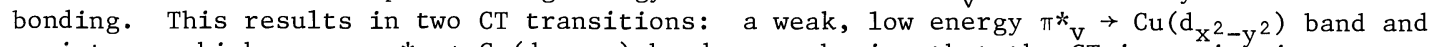

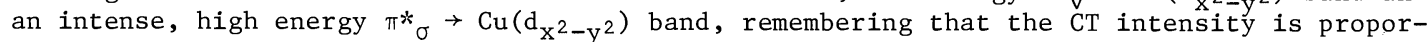
tional to the overlap of the ligand and metal orbitals involved in the transition.

Extending from the monomer to the dimer results in each of these transitions splitting into two, a symmetric and antisymmetric combination. Group theory then predicts (Fig. 14, right) that for $\pi^{*} \mathrm{v}$ one component $\left(\mathrm{A}_{2}\right)$ is only magnetic dipole allowed while the other $\left(\mathrm{B}_{2}\right)$ is electric dipole allowed. Thus the $\mathrm{A}_{2}$ component of $\pi^{*} \mathrm{v}$ should be present in the $\mathrm{CD}$ but not the absorption spectrum, as $\mathrm{CD}$ intensity relates to the magnetic dipole character of a transition. Both of the $\pi *_{\sigma}$ components are electric dipole allowed.

Returning to the oxyhemocyanin absorption and CD spectra shown in Fig. 15, $\pi * \mathrm{v}$ is clearly observed to split into two bands; the $\sim 600 \mathrm{~nm}$ feature is the $\mathrm{B}_{2}$ component while $\mathrm{A}_{2}$ is assigned as the feature at $\sim 480 \mathrm{~nm}$, present in the $\mathrm{CD}$ but absent in the oxy absorption spectrum. The $350 \mathrm{~nm}$ band is the lower energy component of $\pi^{*} \sigma$. The fact that three $\mathrm{O}_{2}=$ CT transitions are observed requires that peroxide bridge the two copper ions (only two transitions are possible for $\mathrm{O}_{2}=$ bound to a single copper(II)).

One can now use the energy and intensity of the $350 \mathrm{~nm}$ band to distinguish between the two possible bridging modes for the peroxide [3]. We approach this problem by treating the $\pi^{*} \sigma$ CT as a transition dipole vector and couple these vectors for the two binding modes of peroxide represented at the top of Fig. 16. The $\mu-1,1$ geometry (Fig. 16, right) predicts the lowest energy component of $\pi *_{\sigma}$ to have only $25 \%$ of the total $\sigma$ intensity. Correlating this with the $350 \mathrm{~nm}$ band in the oxy spectrum gives an unreasonably large total transition dipole 
and $\pi *$ splitting. Alternatively, the $\mu-1,2$ peroxide geometry (Fig. 16, left) predicts the lower energy $\pi *_{\sigma}$ component to have most of the intensity. Associating this with the $350 \mathrm{~nm}$ oxy band results in a reasonable total intensity for the transition dipole and for the splitting of the $\pi *_{\sigma}$ transition; these values are consistent with what is observed for binuclear cobalt $\mu$-peroxide model complexes [17].

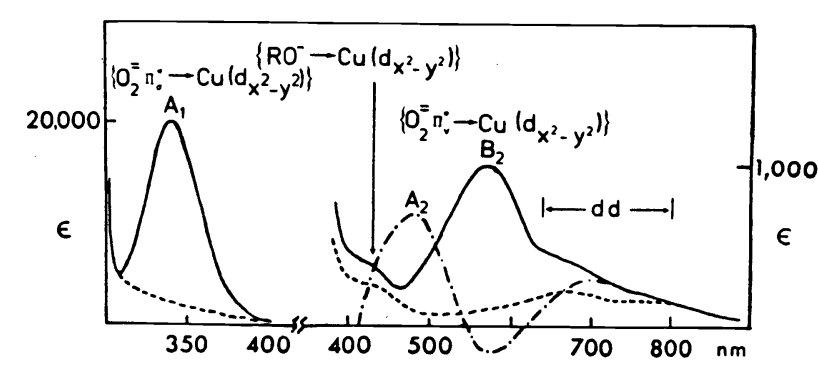

Fig. 15<smiles></smiles>
$\left(\vec{M}_{1}-\vec{M}_{2}\right.$<smiles>C1CCCCC1</smiles>

$\left(\overrightarrow{\mathrm{M}}_{1}+\overrightarrow{\mathrm{M}}_{2}\right)$ $\mu$-monooxo

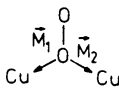

$B_{1}$<smiles>[AlH2]C[AlH2][AlH2]</smiles>

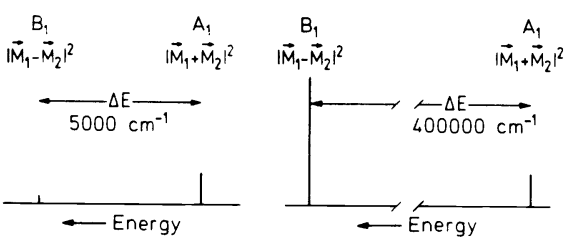

Fig. 16

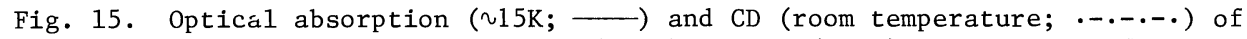
oxyhemocyanin and optical absorption ( $15 \mathrm{~K})$ of met (----); assignment of spectral features is indicated.

Fig. 16. Transition dipole vector coupling analysis of $\pi *_{\sigma} \mathrm{O}_{2}=\rightarrow \mathrm{Cu}$ (II) CT transitions for $\mu-1,2$ bridging peroxide (left) and $\mu-1,1$ bridging peroxide (right) geometries.

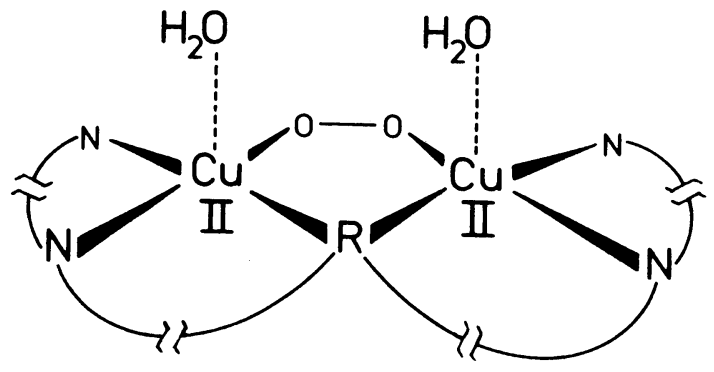

Fig. 17. Spectroscopically effective active site picture of oxyhemocyanin.

In summary of the first half of this talk, we have generated the "spectroscopically effective" picture of the oxyhemocyanin active site shown in Fig. 17. Two tetragonal copper(II)'s are spanned by an endogenous protein bridge (likely phenolate or $\mathrm{OH}^{-}$) which is responsible for the antiferromagnetic coupling and the lack of an EPR signal. The exogenous ligand peroxide bridges in a $\mu-1,2$ geometry producing the unique optical spectral features of $\mathrm{O}_{2}=\rightarrow$ Cu(II) CT transitions to two copper(II)'s. We now extend this chemical-spectroscopic approach to the proteins in Table 1, in order to elucidate structure-function correlations of the coupled binuclear copper site.

\section{STRUCTURE-FUNCTION CORRELATIONS}

Arthropod and Mollusc Hemocyanins

The active site derivatives summarized in Fig. 3 have been prepared for five arthropod and five mollusc hemocyanins. We have found that in general [18], while spectral features within a phylum are extremely similar, quantitative differences exist between phyla. These differences relate to a structural distortion of the active site which interferes with 
exogenous ligand binding at the site. Comparison of the oxy spectra illustrates this point (Fig. 18). The same oxy features appear in the arthropod spectrum; however, the $\pi^{*} v$ components are less split and absorption intensity is mixed into the magnetic dipole allowed higher energy $\mathrm{A}_{2}$ component at $\sim 480 \mathrm{~nm}$. Further, the $\mathrm{d}-\mathrm{d}$ transitions and the $420 \mathrm{~nm} \mathrm{RO}^{-} \rightarrow$ $\mathrm{Cu}$ (II) CT band are enhanced in intensity in the arthropod spectrum. This indicates a tilt in the bridged peroxide relative to the equatorial planes of the coppers which induces the intensity mixing.

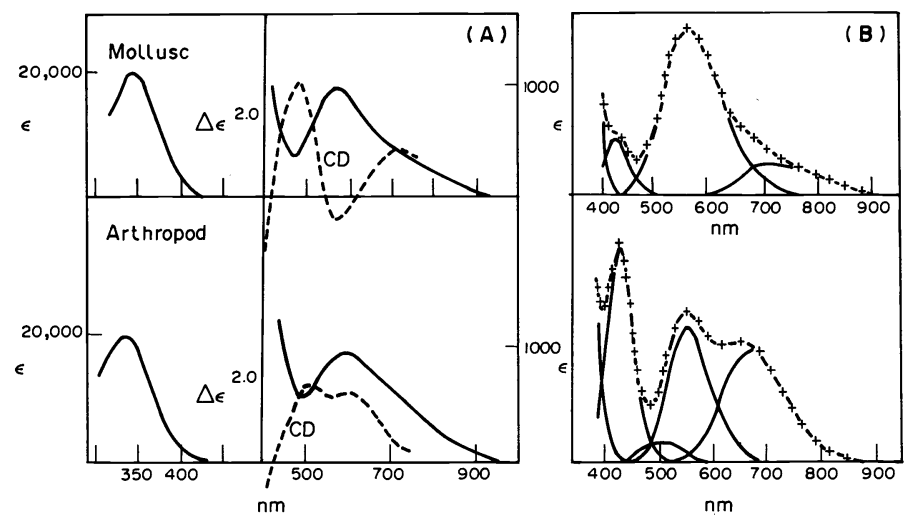

Fig. 18. A, left: room temperature absorption (-) and CD (---); B, right: Gaussian resolution of low temperature ( $15 \mathrm{~K}$ ) absorption spectra of mollusc and arthropod oxyhemocyanin.

The distortion of the arthropod site appears to correlate with its lack of catalase activity. Dismutation of peroxide by mollusc hemocyanins occur through the reaction sequence in Fig. 19. The first peroxide oxidizes deoxy by two electrons to met which then binds the second peroxide to generate oxyhemocyanin; the latter reaction occurs only at the mollusc site.

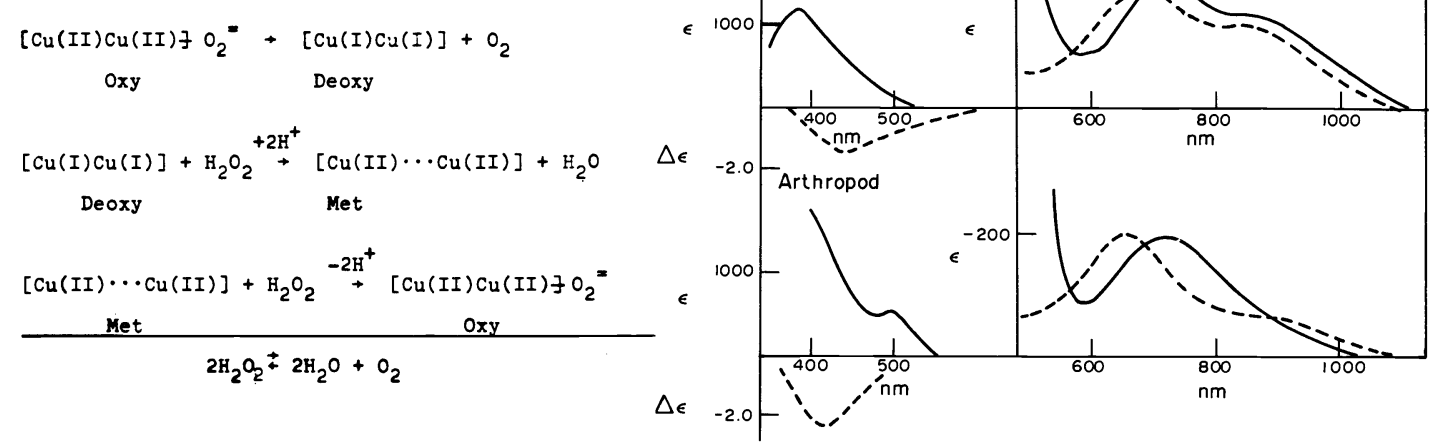

Fig. 19

Fig. 20

Fig. 19. Reaction mechanism of catalase activity in the mollusc coupled binuclear copper site.

Fig. 20. Left: room temperature absorption (-) and CD (----) spectra of met- $\mathrm{N}_{3}^{-}$; right: low temperature $(\sim 15 \mathrm{~K})$ absorption spectra of met- $\mathrm{N}_{3}^{-}(-)$and met-aquo (---) hemocyanin from mollusc (Busycon) and arthropod (Limulus).

The structural distortion of the arthropod met site appears to interfere with peroxide coordination, and hence, regeneration of oxy. We have probed [18] exogenous ligand binding to the met site using the innocent ligand $\mathrm{N}_{3}-$, Fig. 20. Azide coordinates to the mollusc met site with a binding constant $\mathrm{K}=500 \mathrm{M}^{-1}$ producing small changes in the d-d transitions 
and an $\mathrm{N}_{3}^{-} \rightarrow \mathrm{Cu}(\mathrm{II})$ CT spectrum not unlike that normally observed for azide binding equatorially to tetragonal $\mathrm{Cu}(\mathrm{II})$. In contrast, azide binds to the arthropod met site producing a larger shift in the $d-d$ transitions and a significantly different $\mathrm{N}_{3}-\rightarrow \mathrm{Cu}$ (II) CT spectrum. Associated with this distortion in exogenous ligand binding we find that the $\mathrm{N}_{3}{ }^{-}$binding constant has been reduced by two orders of magnitude relative to the mollusc met site.

In collaboration with Professor Thomas G. Spiro, Princeton University and Dr. Linda Powers, Be11 Labs, we have further investigated this distortion by EXAFS spectroscopy [16c]. The Cu K-edge EXAFS of the arthropod and mollusc met sites are shown in Fig. 21. A fit of this data indicates no significant differences between these sites. Thus, the distortion of the arthropod met site which interferes with catalase activity does not relate to changes in number or type of ligation or bond lengths, but must reflect a change in geometry about the copper ions or differences in the protein pocket.

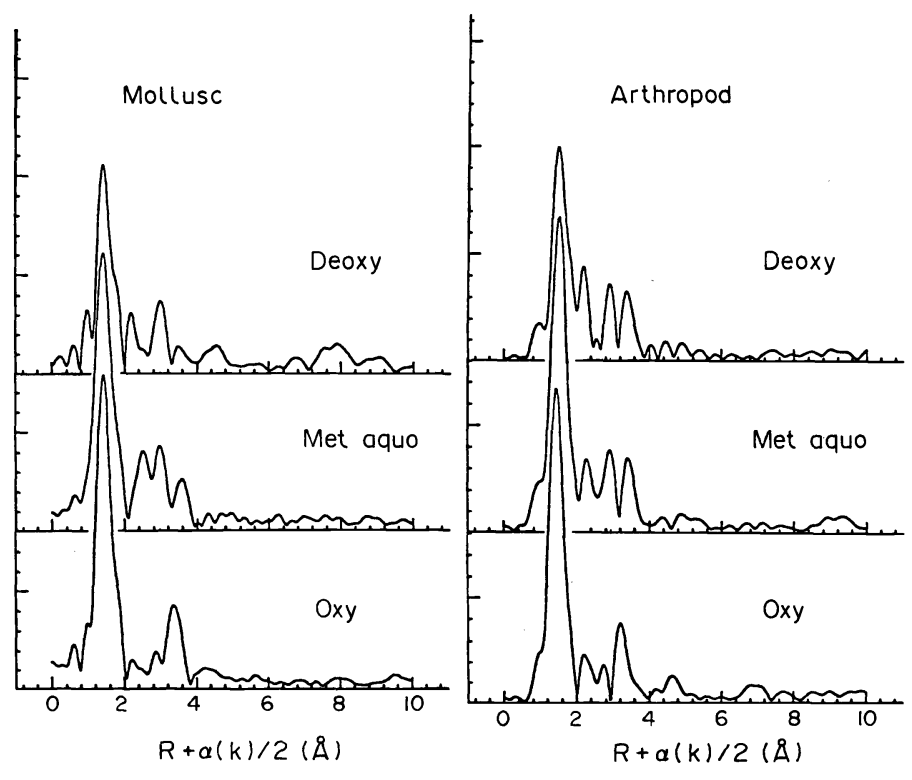

Fig. 21. Fourier Transform of $\mathrm{k}^{3}$ weighted EXAFS spectra of deoxy, met-aquo and oxy mollusc (Busycon) and arthropod (

Hemocyanin cooperativity

EXAFS spectroscopy [16] has also been used to probe active site changes upon deoxygenation (Fig. 21). The outer she11 peak in the oxyhemocyanin Fourier Transform (FT) relates to scattering from the second copper and indicates a $\mathrm{Cu}-\mathrm{Cu}$ distance of $\sim 3.6 \AA$. Upon deoxygenation, assignment of the outer shell peaks becomes less clear. However, fitting a second copper to this region indicates [16c] little change in $\mathrm{Cu}-\mathrm{Cu}$ distance (deoxy $23.4 \AA$ ). The dominant effect appears to be a change in ligation, as indicated by a decrease in the intensity of the first shell peak in the FT.

Through the preparation of a "spectral probe" derivative of the hemocyanin biopolymer [19], we have further studied the changes in active site structure upon deoxygenation to investigate protein cooperativity. The molecular architecture of the hemocyanin quaternary structure is extremely complicated. One mollusc subunit consists of a single polypeptide chain of 400,000 daltons and contains eight binuclear copper active sites; under physiological conditions twenty of these subunits aggregate to produce the whole molecule containing $\sim 160$ active sites (Fig. 22). The "spectral probe" derivative we have prepared contains $15 \%$ EPR-detectable half met sites dispersed among the $285 \%$ EPR-nondetectable oxy sites.

If we monitor the probe sites by EPR and deoxygenate the oxy sites, we observe little change in the spectrum, as shown in Fig. 23, left. However, deoxygenation in the presence of $\mathrm{Ca}^{2+}$, a heterotropic effector required for cooperative intersite interaction in the mollusc hemocyanins, leads to a shift of the protein from relaxed to tensed quaternary structure and produces large changes in the mixed valent EPR spectrum of the half met spectral probe (Fig. 23, right). Our preliminary interpretation of these spectral changes (which are now being studied in detail) indicates they dominantly involve the endogenous bridge becoming more sterically competitive at the deoxy site. 


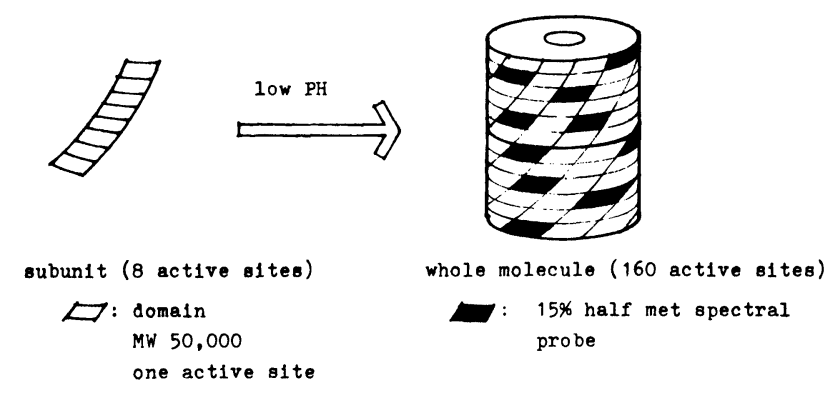

Fig. 22
Without $\mathrm{Co}^{2+} \quad$ With $\mathrm{Co}^{2+}$
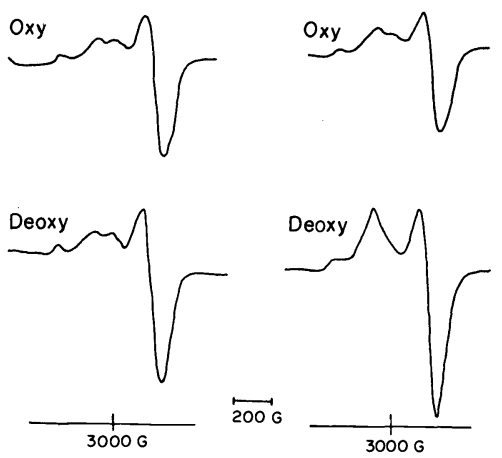

Fig. 23

Fig. 22. Molecular architecture of the mollusc (Busycon) hemocyanin spectral probe derivative.

Fig. 23. EPR spectra (77K) and calcium effects on Busycon spectral probe with 100 fold excess $\mathrm{N}_{3}{ }^{-}$in oxy (upper) and deoxy (lower) states.

\section{Tyrosinase}

We now correlate our chemical-spectroscopic approach on the coupled binuclear copper site in hemocyanin to parallel studies on tyrosinase, in collaboration with Dr. Konrad Lerch, Universität Zürich. Our studies [20] indicate that the active site in tyrosinase is extremely similar to that of the hemocyanins (Fig. 17). Oxytyrosinase can be prepared, and exhibits a CT spectrum (Fig. 24) very similar to that of oxyhemocyanin. Resonance Raman excitation into the UV absorption (Fig. 25) produces an 0-0 stretching frequency of $755 \mathrm{~cm}^{-1}$ indicating

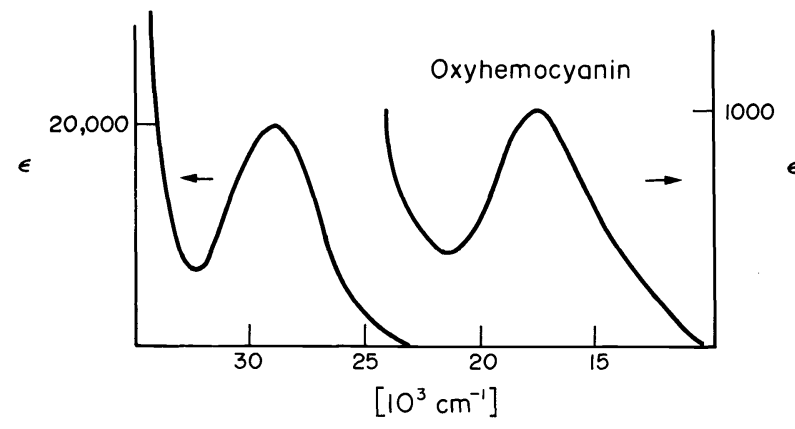

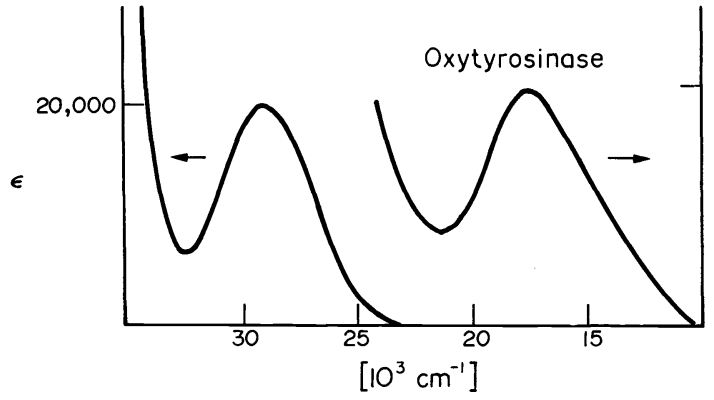

Fig. 24

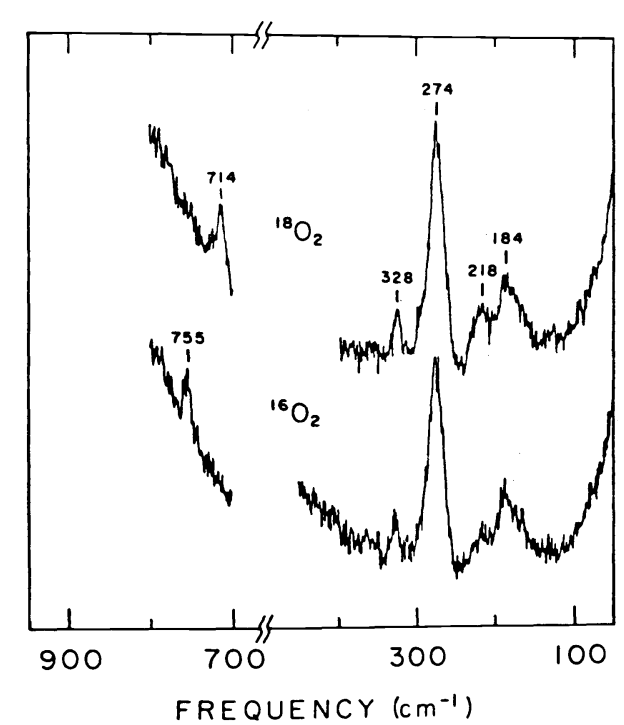

Fig. 25

Fig. 24. Room temperature absorption spectra of oxyhemocyanin and oxytyrosinase.

Fig. 25. Resonance Raman spectra of ${ }^{18} \mathrm{O}_{2}$ and ${ }^{16} \mathrm{O}_{2}$ oxytyrosinase; $200 \mathrm{~mW}, 363.8 \AA$ excitation. 
that dioxygen is bound as peroxide and that oxygen activation does not differ between these two proteins [21]. All of the binuclear copper active site derivatives of hemocyanin (Fig. 3) have been prepared for tyrosinase, and their chemical-spectroscopic properties also indicate that tyrosinase has a very similar active site. For example, the half met derivative (Fig. 26) shows large EPR changes upon addition of the exogenous ligand $\mathrm{N}_{3}{ }^{-}$. Extensive dialysis produces an EPR signal different from the original indicating tight binding of $\mathrm{N}_{3}{ }^{-}$

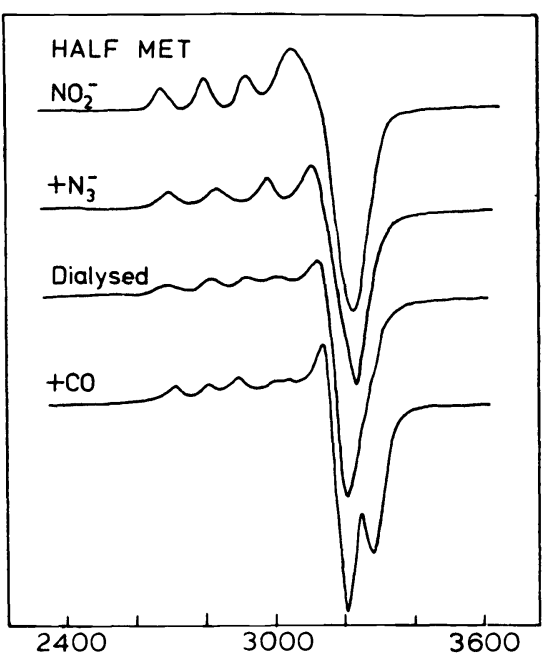

Fig. 26
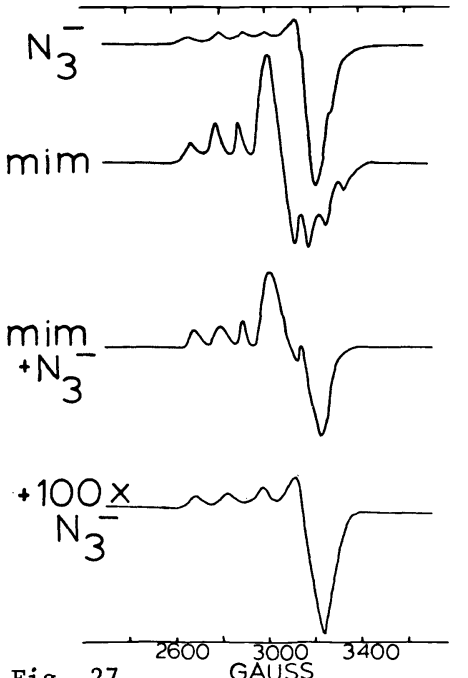

Fig. 27
Mimosine<smiles>NC(Cn1ccc(=O)c(O)c1)C(=O)[O-]</smiles>

Fig. 26. EPR spectra (77K) of half met- $\mathrm{NO}_{2}^{-}$tyrosinase, half met- $\mathrm{N}_{3}^{-}$in excess $\mathrm{N}_{3}{ }^{-}$, excess $\mathrm{N}_{3}^{-}$dialyzed off, and treated with 30 psi CO.

Fig. 27. Tyrosinase EPR spectra $\left(77 \mathrm{~K}\right.$ ) of half met- $\mathrm{N}_{3}{ }^{-}$, half met-mimosine, half met ternary complex of azide and mimosine, and half met-mimosine with excess azide (after $24 \mathrm{hrs}$ ).

due to the presence of $\mathrm{Cu}(\mathrm{I})$. Coordination of $\mathrm{CO}$ to the $\mathrm{Cu}(\mathrm{I})$ changes the EPR signal of the $\mathrm{Cu}(\mathrm{II})$ and labilizes the $\mathrm{N}_{3}{ }^{-}$. Parallel to hemocyanin chemistry, this behavior confirms exogenous ligand bridging between the two coppers. Studies on met and dimer further demonstrate an endogenous protein bridge, and analysis (Fig. 16) of the $0_{2}=\rightarrow \mathrm{Cu}$ (II) CT spectrum of oxytyrosinase (Fig. 24) indicates a $\mu-1,2$ bridging geometry as found for oxyhemocyanin.

The major differences we have found in tyrosinase relate to the accessibility of this coupled binuclear copper active site to organic substrates [20,22]. We can probe site accessibility by comparing the pseudo first order rates of associative peroxide displacement from the oxy site by exogenous ligands. In the case of $\mathrm{N}_{3}{ }^{-}$, we find the rates differ by four orders of magnitude over a series of hemocyanins and tyrosinase, with tyrosinase having by far the most accessible site (Table 2). This accessibility directly correlates with substrate (phenol) turnover and organic competitive inhibitor (e.g., mimosine) binding.

As shown in Fig. 27 for the half met derivative, mimosine coordinates [23] to the copper site producing a very unusual EPR signal. Addition of the small molecule analogue $\mathrm{N}_{3}{ }^{-}$produces a change in the half met EPR signal indicating formation of a ternary active site complex; further addition of excess $\mathrm{N}_{3}^{-}$eventually displaces the mimosine from the active site. Thus, both the small molecule and competitive inhibitor bind to the coupled binuclear copper active site and compete with one another for the same binding site. These results led to the structural mechanism [23] for the tyrosinase reactivity of the oxy coupled binu-

TABLE 2. Rates of peroxide displacement

\begin{tabular}{|c|c|c|c|c|}
\hline & Tyrosinase & Cancer & Busycon & Limulus \\
\hline $\mathrm{pH}_{3}^{-}$ & $0.95 \mathrm{hr}^{-1}$ & $0.04 \mathrm{hr}^{-1}$ & $0.002 \mathrm{hr}^{-1}$ & $\ll 10^{-4} \mathrm{hr}^{-1}$ \\
\hline $\begin{array}{c}\text { mimosine } \\
\mathrm{pH} 6.3\end{array}$ & $162 \mathrm{hr}^{-1}$ & $\ll 10^{-4} h r^{-1}$ & $\ll 10^{-4} h^{-1}$ & $\ll 10^{-4} \mathrm{hr}^{-1}$ \\
\hline $\begin{array}{l}\text { phenol } \\
\text { pH } 5.0\end{array}$ & $\begin{array}{l}\text { fast } \\
\text { substrate }\end{array}$ & $1.83 \mathrm{hr}^{-1}$ & $0.021 \mathrm{hr}^{-1}$ & - \\
\hline
\end{tabular}


clear copper active site shown in Fig. 28. First the monophenol coordinates axially to one of the $\mathrm{Cu}(\mathrm{II})$ 's. An associative trigonal bipyramidal rearrangement (as is normally found for tetragonal $\mathrm{Cu}(\mathrm{II})$ ) of the ternary active site complex labilizes the peroxide and produces a site with the monophenol and peroxide both coordinated equatorially and oriented appropriately for o-hydroxylation. Oxidation of the resultant equatorially bound catechol produces o-quinone and two $\mathrm{Cu}(\mathrm{I})$ 's leading to product dissociation and a deoxy site capable of further turnover.

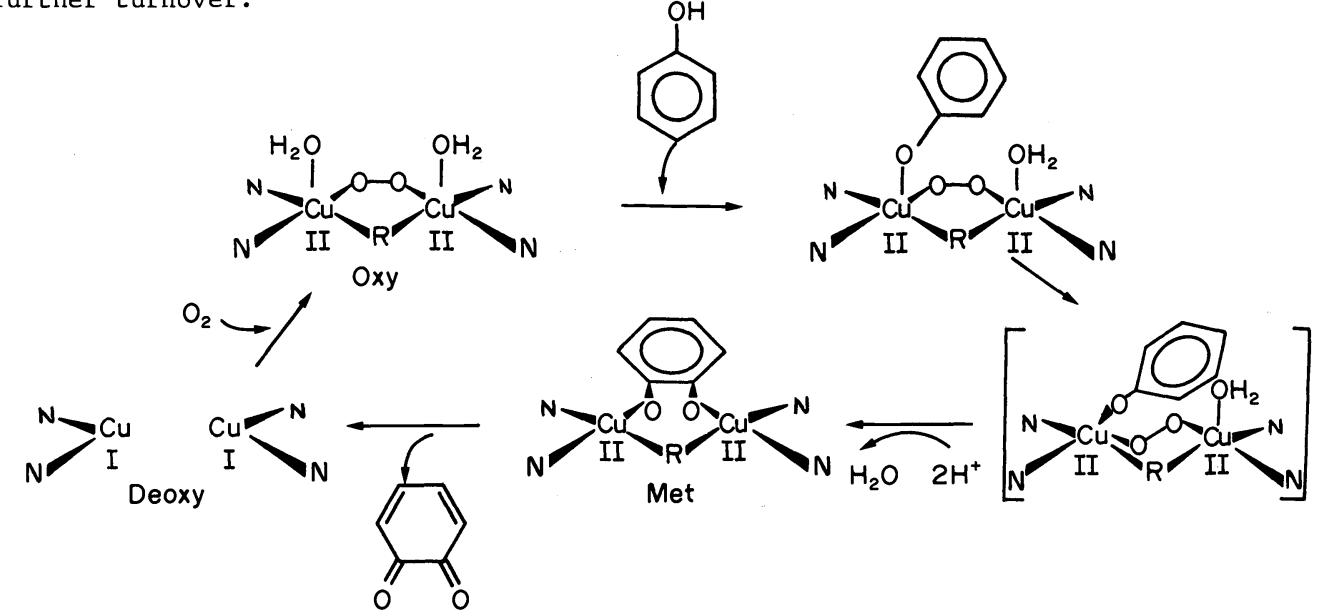

Fig. 28. Active site structural mechanism of hydroxylation and oxidation of phenols to form o-diquinones by tyrosinase.

We have now studied [22] a series of substrate analogues bound to the coupled binuclear copper site in tyrosinase and have found little interaction of the aromatic ring with residues of the protein pocket. However, we do find that aromatics conjugated to the coordinating group (e.g., benzoate and toluate in Fig. 29) form thermodynamically more stable complexes with the site. This appears to correlate to electronic interactions with the coppers producing the characteristic half met EPR signals shown in Fig. 29 which, like half met mimosine (Fig. 27), exhibit large hyperfine coupling in the perpendicular region. Further studies of these electronic effects are underway.

Half met tyrosinase

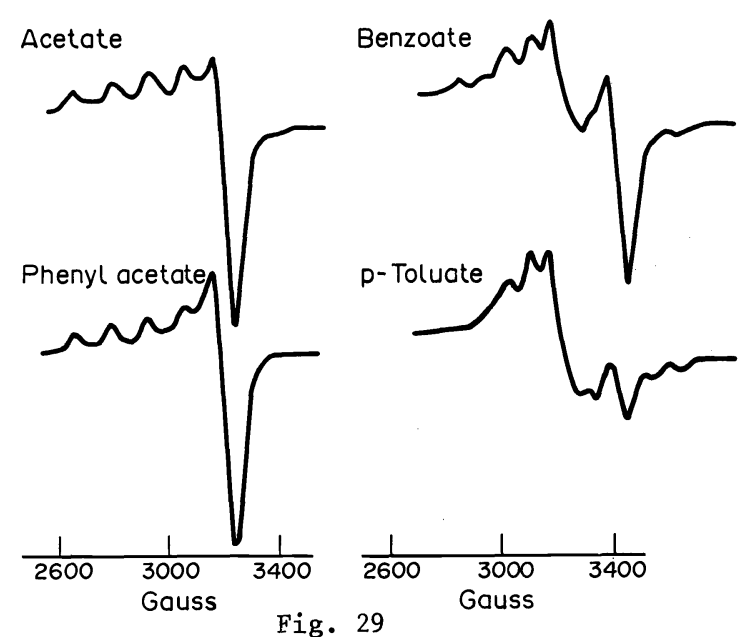

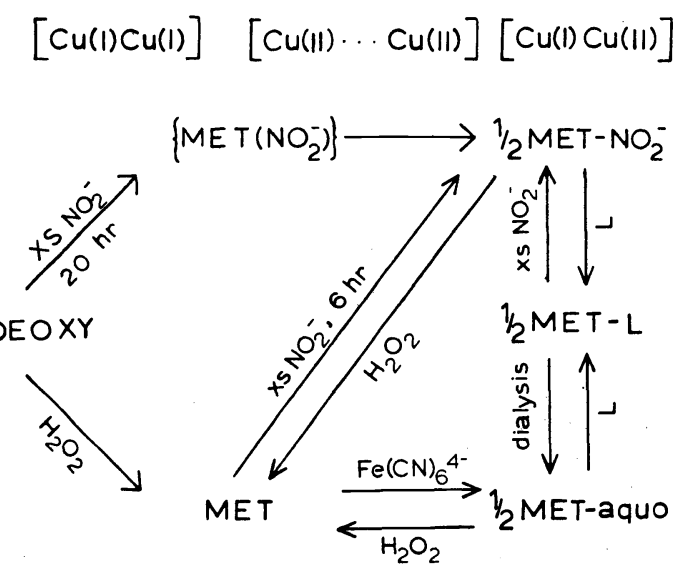

Fig. 30

Fig. 29. EPR spectra (77 K) of half met tyrosinase in the presence of competitive non-conjugated (left) and conjugated (right) carboxylate inhibitors.

Fig. 30. Reactivity and derivatives of the binuclear copper site in T2D Rhus laccase.

Laccase

In the last part of this lecture we extend this chemical-spectroscopic approach to the coupled binuclear copper (type 3 ) site in the least complicated multicopper oxidase, Rhus laccase [24]. Here, in addition to the type 3 site, type 1 (or blue) and type 2 (or normal) copper centers are present. Together, these couple four one-electron outer sphere oxidations of substrate at the type 1 site to the four-electron reduction of dioxygen to water through a two-electron reduced peroxide intermediate at the type 3 site. An important chemical simplification of this enzyme has been the reversible removal of the type 2 copper in Rhus laccase, producing the type 2 depleted (T2D) derivative [25]. As shown in Fig. 30, stable 
derivatives of the coupled binuclear copper site in T2D laccase have also been prepared [26, 27] which parallel those of the hemocyanins and tyrosinase, but which indicate significant differences in exogenous ligand binding to the type 3 site [27-29]. Deoxy contains two $\mathrm{Cu}(\mathrm{I})$ 's which are stable to oxidation by dioxygen. However, NO and $\mathrm{H}_{2} \mathrm{O}_{2}$ will oxidize [30] these centers to form the met [ $\mathrm{Cu}(\mathrm{II}) \mathrm{Cu}(\mathrm{II})]$ derivative. Further one-electron reduction by NO or $\mathrm{Fe}(\mathrm{CN})_{6}{ }^{4-}$ produces the half met $[\mathrm{Cu}(\mathrm{II}) \mathrm{Cu}(\mathrm{I})]$ form.

A spectroscopic comparison of met T2D laccase with met hemocyanin (Fig. 31) indicates significant similarities between these binuclear copper sites. Met T2D laccase, like met hemocyanin, exhibits d-d transitions in the $750 \mathrm{~nm}$ region requiring that the lack of EPR signal be due to antiferromagnetic coupling between two tetragonal copper(II)'s, and hence, the

\section{LACCASE}

\section{A $\underline{E P R}$}

non detectable

\section{B OPTICAL FEATURES}

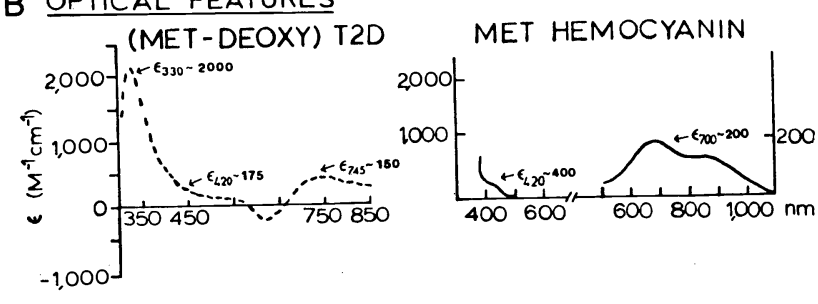

\section{EXAFS}
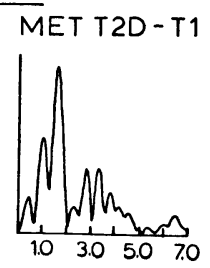

\section{HEMOCYANIN}

\section{non detectable}

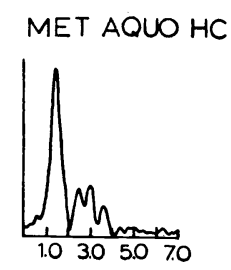

Fig. 31. Spectroscopic comparison of met T2D Rhus laccase (left) and met Busycon hemocyanin (right). B: room temperature difference absorption spectrum (met-deoxy) T2D (---) and absorption spectrum of met hemocyanin (-). C: FT of Difference EXAFS spectrum of plastocyanin subtracted met T2D (left) and FT EXAFS spectrum of met aquo hemocyanin (right).

presence of an endogenous protein bridge $\left(R^{\prime}\right)$. Further, met T2D shows an absorption feature at $\sim 420 \mathrm{~nm}$ which is similarly observed in hemocyanin, and has in the latter protein been assigned as $\mathrm{RO}^{-} \rightarrow \mathrm{Cu}(\mathrm{II}) \mathrm{CT}$ likely relating to the bridge. In addition, laccase exhibits a fairly intense, sharp band at $\sim 330 \mathrm{~nm}$; absorption in this region is somewhat weaker and broader in met hemocyanin. As tetragonal sulfur $\rightarrow \mathrm{Cu}$ (II) $\mathrm{CT}$ will contribute in this region, EXAFS studies [31], in collaboration with Professor Keith Hodgson, Stanford University, were used to probe the possibility of sulfur coordination at the type 3 site. The first shell peak in the met T2D FT difference EXAFS spectrum (Fig. 31, bottom) clearly excludes sulfur ligation and requires an average of $3-4 \mathrm{~N}$ or 0 ligands per copper center, in parallel with met hemocyanin [16]. Based on model studies [2], the intensity at $330 \mathrm{~nm}$ then likely derives from a composite of $\mathrm{His} \rightarrow \mathrm{Cu}(\mathrm{II}) \mathrm{CT}$ transitions.

While the met comparison of T2D laccase and hemocyanin indicates similarities both in ligation at the sites and in the presence of an endogenous bridge between two tetragonal copper(II)'s, chemical and spectral studies of the half met derivative indicate significant differences with respect to exogenous ligand binding. As shown in Fig. 32 (left), addition of excess $\mathrm{N}_{3}^{-}$to half met T2D produces a change in the EPR signal of the type 3 site, indicating coordination by $\mathrm{N}^{-}$(note that the type 1 site is oxidized and also contributes to the EPR spectra in Fig. 32). However, in strong contrast to the tight binding of exogenous ligands in half met hemocyanin, due to bridging to the copper(I) (Fig. 32, right), short term dialysis of half met- $\mathrm{N}_{3}-\mathrm{T} 2 \mathrm{D}$ produces the original half met-aquo EPR signal indicating normal, labile tetragonal Cu(II) ligand substitution chemistry. In all of our half met and 
met T2D laccase studies, there has been no evidence for exogenous ligand bridging between the two copper ions.
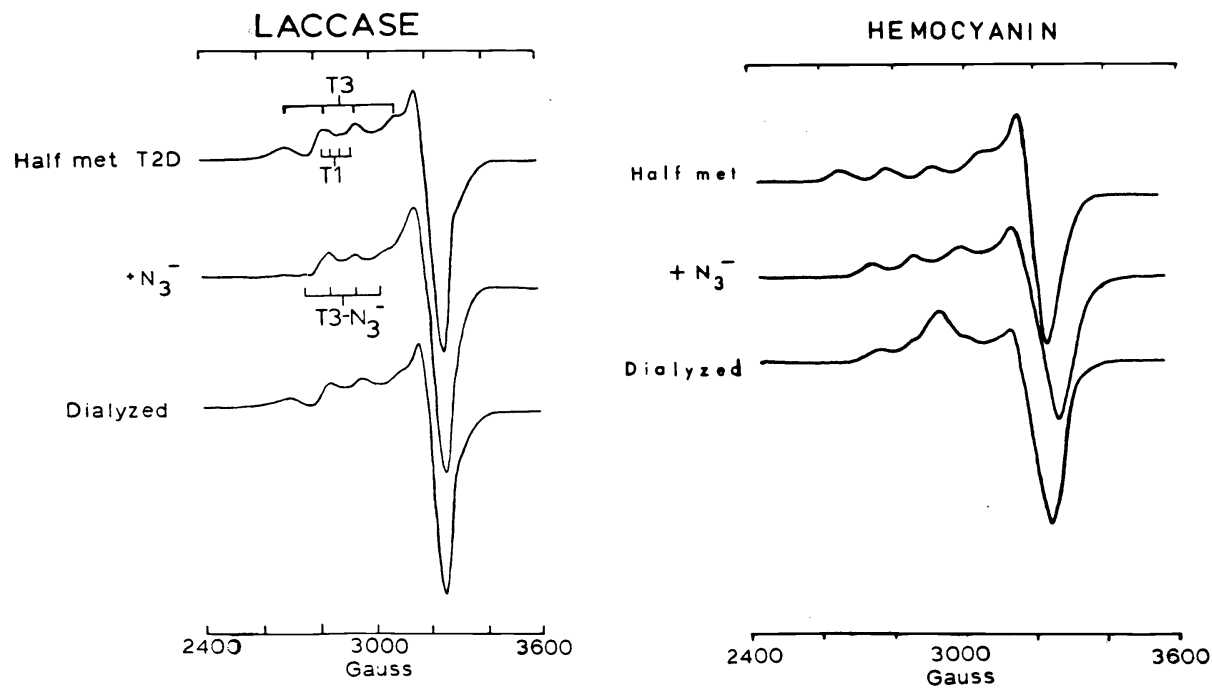

Fig. 32. EPR (77 K) spectral comparison of (1eft) half met T2D laccase, and (right) half met hemocyanin, + excess $\mathrm{N}_{3}{ }^{-}$, dialyzed.

This lack of exogenous ligand bridging also extends to peroxide binding to the type 3 site in native laccase (Fig. 33). In oxyhemocyanin, two dominant $\mathrm{O}_{2}=\rightarrow \mathrm{Cu}$ (II) CT bands are observed in the absorption spectrum ( 600 and $350 \mathrm{~nm}$ ) and a thîrd in the CD ( 480 nm) which are interpreted in terms of a $\mu-1,2$ peroxy bridge. Addition of peroxide to laccase produces little change in the $\mathrm{CD}$ spectrum and only a weak absorption band $\left(\varepsilon<1000 \mathrm{M}^{-1} \mathrm{~cm}^{-1}\right)$ at $\sim 320$ $\mathrm{nm}[28,32]$ clearly indicating a different peroxide binding mode to the type 3 site in laccase, consistent with the lack of exogenous ligand bridging.

Peroxide binding

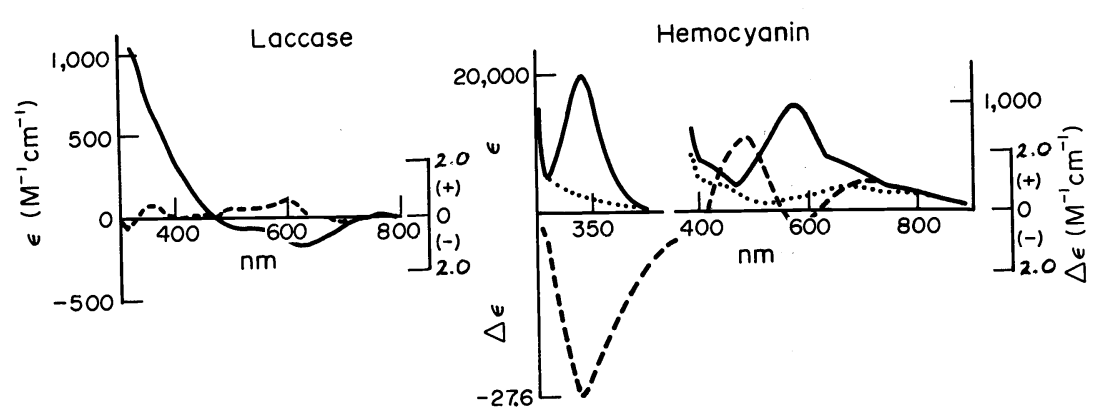

Fig. 33. Optical features associated with peroxide binding to the coupled binuclear copper sites in native laccase and hemocyanin. Left: laccase, room temperature difference absorption (-) and difference $\mathrm{CD}(---)$ of (native $+30 \mathrm{X} \mathrm{H}_{2} \mathrm{O}_{2}$ ) vs. (native), $\mathrm{pH}=6.0$. Right: hemocyanin, $\sim 15 \mathrm{~K}$ absorption spectra of oxy $(\stackrel{2}{-})$ and met $(\cdots \cdots)$, and room temperature $C D$ spectrum of oxy (---).

We have thus generated the preliminary "spectroscopically effective" model for the coupled binuclear copper active site of laccase shown in Fig. 34. In contrast to hemocyanin which reversibly binds dioxygen as a $\mu-1,2$ peroxy bridge, peroxide coordinates to only one of the type 3 coppers in laccase. This likely relates to the irreversible binding of this dioxygen 
intermediate for its further reduction to water. However, the hydroperoxide does not bind strongly in this geometry without the presence of the type 2 copper, which apparently stabilizes the hydroperoxide bound at the type 3 site. Further studies are directed toward understanding this type 2 interaction with the coupled binuclear type 3 copper site.<smiles>[R]O[Ge](C)(C)OO[Ge](C)(C)C</smiles>

HEMOCYANIN and TYROSINASE

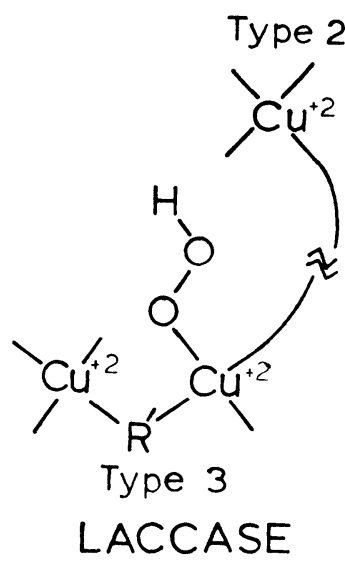

Fig. 34. Spectroscopically effective active site representations of the hemocyanin and tyrosinase coupled binuclear copper site (left) and the type 3 site in Rhus laccase (right) where $O R$ and $R^{\prime}$ represent endogenous protein bridges in the respective sites.

Acknowledgement - Support by the National Institutes of Health (Grant AM 31450) is gratefully acknowledged. I would also like to thank my students, Nancy Eickman, Richard Himmelwright, Yeong Hwang, Cynthia LuBien, Darlene Spira, Thomas Thamann, Dean Wilcox and Marjorie Winkler, and collaborators Keith Hodgson, Konrad Lerch, William Mims and Thomas Spiro, who have contributed to various portions of this work.

\section{REFERENCES}

1. E.I. Solomon, Copper Proteins (ed. T.G. Spiro), chapter 2, Wiley-Interscience, New York, (1981).

2. E.I. Solomon, K.W. Penfield and D.E. Wilcox, Structure and Bonding 53, 1-57 (1983).

3. N.C. Eickman, R.S. Himmelwright and E.I. Solomon, Proc. Nat. Acad. Sci. USA 76, 20942098 (1979).

4. J.S. Loehr, T.B. Freedman and T.M. Loehr, Biochem. Biophys. Res. Comm. 56, 510-515 (1974).

5. (a) E.I. Solomon, D.M. Dooley, R.-H. Wang, H.B. Gray, M. Cerdonio, F. Mogno and G.L. Romani, J. Am. Chem. Soc. 98, 1029-1031 (1976); (b) D.M. Dooley, R.A. Scott, J. Ellinghaus, E.I. Solomon and H.B. Gray, Proc. Nat. Acad. Sci. USA 75, 3019-3022 (1978).

6. R.S. Himmelwright, N.C. Eickman and E.I. Solomon, Biochem. Biophys. Res. Comm. 81, 243247 (1978).

7. R.S. Himmelwright, N.C. Eickman and E.I. Solomon, J. Am. Chem. Soc. 101, 1576-1586 (1979).

8. (a) R.S. Himmelwright, N.C. Eickman and E.I. Solomon, Biochem. Biophys. Res. Comm. 81, 237-242 (1978); (b) R.S. Himmelwright, N.C. Eickman and E.I. Solomon, Biochem. Biophys. Res. Comm. 84, 300-305 (1978).

9. A.J.M. Schoot Uiterkamp, FEBS Lett. 20, 93-96 (1972).

10. R. Witters and R. Lontie, FEBS Lett. 60, 400-403 (1965).

11. R.S. Himmelwright, N.C. Eickman and E.I. Solomon, Biochem. Biophys. Res. Comm. $\underline{86}$, 628634 (1979).

12. D.E. Wilcox, W.B. Mims and E.I. Solomon, to be published.

13. W.B. Mims, The Linear Electric Field Effect in Paramagnetic Resonance, Clarendon, Oxford $(1976)$.

14. A.J.M. Schoot Uiterkamp, H. van der Deen, H.C.J. Berendsen and J.F. Boas, Biochim. Biophys. Acta 372, 407-425 (1974).

15. D.E. Wilcox, J.R. Long and E.I. Solomon, manuscript in preparation.

16. (a) J.M. Brown, L. Powers, B. Kincaid, J.A. Larrabee and T.G. Spiro, J. Am. Chem. Soc. 
102, 4210-4216 (1980); (b) M.S. Co, K.0. Hodgson, T.K. Eccles and R. Lontie, J. Am. Chem. Soc. 103, 984-986 (1981); (c) G.L. Woolery, T.G. Spiro, L. Powers, M.E. Winkler and E.I. Solomon, submitted to J. Am. Chem. Soc.; (d) M.S. Co and K.O. Hodgson, J. Am. Chem. Soc. 103, 3200-3201 (1981).

17. A.B.P. Lever and H.B. Gray, Acc. Chem. Res. 11, 348-355 (1978).

18. R.S. Himmelwright, N.C. Eickman, C.D. LuBien and E.I. Solomon, J. Am. Chem. Soc. 102, 5378-5388 (1980).

19. Y.T. Hwang and E.I. Solomon, Proc. Nat1. Acad. Sci. USA 79, 2564-2568 (1982).

20. R.S. Himmelwright, N.C. Eickman, C.D. LuBien, K. Lerch and E.I. Solomon, J. Am. Chem. Soc. 102, 7339-7344 (1980).

21. N.C. Eickman, E.I. Solomon, J.A. Larrabee, T.G. Spiro and K. Lerch, J. Am. Chem. Soc. $100,6529-6531$ (1978).

22. M.E. Winkler, Y.T. Hwang, K. Lerch and E.I. Solomon, to be published.

23. M.E. Winkler, K. Lerch and E.I. Solomon, J. Am. Chem. Soc. 103, 7001-7003 (1981).

24. (a) B. Reinhammar and B.G. Malmström, Copper Proteins (ed. T.G. Spiro), chapter 3, Wiley-Interscience, New York (1981); (b) O. Farver and I. Pecht, ibid, chapter 4.

25. M.T. Graziani, L. Morpurgo, G. Rotilio and B. Mondovi, FEBS Lett. 70, 87-90 (1976).

26. C.D. LuBien, M.E. Winkler, T.J. Thamann, R.A. Scott, M. S. Co, K.o. Hodgson and E.I. Solomon, J. Am. Chem. Soc. 103, 7014-7016 (1981).

27. D.J. Spira, M.E. Winkler and E.I. Solomon, Biochem. Biophys. Res. Comm. 107, 721-726 (1982).

28. M.E. Winkler, D.J. Spira, C.D. LuBien, T.J. Thamann and E.I. Solomon, Biochem. Biophys. Res. Comm. 107, 727-734 (1982).

29. D.J. Spira and E.I. Solomon, submitted to Biochem. Biophys. Res. Comm.

30. J.E. Hahn, M.S. Co, D.J. Spira, K.O. Hodgson and E.I. Solomon, submitted to Biochem. Biophys. Res. Comm.

31. D.J. Spira, M.S. Co, E.I. Solomon and K:O. Hodgson, submitted to Biochem. Biophys. Res. Comm.

32. O. Farver, M. Goldberg and I. Pecht, Eur. J. Biochem. 104, 71-77 (1980). 